\title{
Assessment of Fracture Resistance of Maxillary First Molars after Root Canal Preparation Using Three Different Rotary Instruments (V-Taper, ProTaper, Vortex Blue): Finite Element Analysis
}

mehran malakpour

West Virgina University, memalakpour@mix.wvu.edu

Follow this and additional works at: https://researchrepository.wvu.edu/etd

Part of the Endodontics and Endodontology Commons

\footnotetext{
Recommended Citation

malakpour, mehran, "Assessment of Fracture Resistance of Maxillary First Molars after Root Canal Preparation Using Three Different Rotary Instruments (V-Taper, ProTaper, Vortex Blue): Finite Element Analysis" (2019). Graduate Theses, Dissertations, and Problem Reports. 7456.

https://researchrepository.wvu.edu/etd/7456

This Thesis is protected by copyright and/or related rights. It has been brought to you by the The Research Repository @ WVU with permission from the rights-holder(s). You are free to use this Thesis in any way that is permitted by the copyright and related rights legislation that applies to your use. For other uses you must obtain permission from the rights-holder(s) directly, unless additional rights are indicated by a Creative Commons license in the record and/ or on the work itself. This Thesis has been accepted for inclusion in WVU Graduate Theses, Dissertations, and Problem Reports collection by an authorized administrator of The Research Repository @ WVU. For more information, please contact researchrepository@mail.wvu.edu.
} 
Assessment of Fracture Resistance of Maxillary First Molars after Root Canal Preparation Using Three Different Rotary Instruments (V-Taper, ProTaper, Vortex Blue):

Finite Element Analysis

Mehran Malakpour, D.D.S.

Thesis submitted to the School of Dentistry

At West Virginia University

In partial fulfillment of the requirements

For the degree of

Master of Science

In

Endodontics

Susan Morgan, D.D.S., M.S., Committee Chairperson

Shelia Price, D.D.S., EdD., M.A.

Keith Hildebrand, D.D.S., M.S.

Department of Endodontics

Morgantown, West Virginia

2019

Keywords: Endodontics, Cemento enamel junction, Finite Element Analysis, Nickle-Titanium alloy, Newton, Megapascal, Crack tooth, Precervical dentin, Taper 


\begin{abstract}
Assessment of Fracture Resistance of Maxillary First Molars after Root Canal Preparation Using Three Different Rotary Instruments (V-Taper, ProTaper, Vortex Blue):

Finite Element Analysis

Mehran Malakpour, D.D.S.
\end{abstract}

Introduction: Long term success of endodontically treated teeth has been one of the most challenging aspects of the field of endodontics due to reduced fracture resistance of these teeth. Recently, researchers have heightened focus on conservative endodontics in order to sustain the tooth integrity, and reduce factors impacting the fracture resistance of endodontically treated teeth. As a result, rotary instrument manufacturers have developed files that have a minimal effect on original root canal anatomy. This study used Finite Element Analysis to investigate the dental biomechanical effect of rotary instrumentation during root canal therapy. The aim of this study is to compare the effect of three rotary file systems (VTaper, ProTaper, Vortex Blue) with different tapers on fracture resistance of endodontically treated teeth in the presence of various static and dynamic forces applied to different parts of the coronal part of teeth.

Materials and Methods: In this study, 3D printed acrylic maxillary first molar from Dental Engineering Laboratories LLC DBA DELabs (True Tooth ${ }^{\mathrm{TM}}$ ) was used as the prototype of the research model. The original geometry was modified and prepared for using Spaceclaim software for ANSYS modeling and analysis. The three experimental groups and one control group were created. The ANSYS Boolean operations were done in order to generate four different experimental CAD models. Group one was ProTaper, group two was Vortex Blue and group three was V-Taper. Young modulus and Poisson ratio of all the materials (Enamel, Dentin, Gutta-Percha, Composite) were used for ANSYS software to recognize these volumes and the constituents that are contained within these individual spaces. In this study seven total contact points were considered on the occlusal surface of the models during the chewing cycle. The Von Mises stress and maximum principal stress on the cervical region were computed and analyzed in four different cross sections of pre cervical dentin.

Results: The highest Von Mises stress was observed in the ProTaper group although V-Taper and Vortex Blue groups showed homogeneous stress distributions in the cervical regions as well. Tensile stress was concentrated on the palatal side of the palatal root and the distal portion of the distobuccal (DB) root in all the experimental groups. However, the control group had the least amount of stressed area followed by V-Taper group, Vortex Blue and ProTaper.

Conclusion: Taper size of endodontic files appears to be one of many factors which affect the distribution of forces along the root structure. Preserving dental hard tissue in precervical dentin significantly reduces the stress concentration in the cervical region and increases the ultimate fracture resistance of the tooth. 


\section{Dedication}

To my parents, Majid and Tahereh and my wife, Kiana: Thank you for always being there for me. Your encouragement and support have shaped me to become who I am today. I am forever appreciative of everything that you have done for me. I love you all. 


\section{Acknowledgements}

Dr. Samuel Dorn - Thank you for your mentorship and guidance over the past few months. Your tips from many years of experience have been tremendously helpful.

Dr. Larry Hildebrand - Thank you for teaching me all the fundamentals of endodontics during dental school and sparking my interest and sense of curiosity in this field. Also thank you for accepting me and giving me the opportunity to pursue a career in endodontics.

Dr. Mark Byron - Thank you for your guidance and you taking over the leadership of the program in such a critical time. Your transition to Graduate Endodontics Director has been seamless and the wealth of knowledge you have to share has been priceless.

Dr. Tom Borgia - Thank you for accepting me into the program. Your leadership of WVU School of dentistry has been inspiring. Thank you for all the attention that you have given to the endodontic program and making the residency one of the top programs in the country.

Dr. Susan Morgan - Thank you for serving as chair of my committee. Your expertise in dental research was crucial in guiding me through this process.

Dr. Shelia Price - I never forget your phone call for accepting me into dental school. You changed my life forever. And thank you for all your help and guidance throughout my dental career and your continuous support during residency.

Mr. Chris Waters - This project would not have taken off without your help or support. You are much appreciated, and I can't thank you enough.

Dr. Nima Zamani - Thank you for staying patient with me and explaining the details of how FEA works. I cannot thank you enough for taking time off of your busy schedule and work with me after hours and over weekends to complete this project. This project was not possible if I had not found your department and skills.

Dr. Cade Brawley - I could have not asked for a better co-resident! You have been always there for me in the past few years. I always admired your clinical skills and your interactions with the patients. You really made this residency a much better experience for me and I am very thankful for that. I wish you the best of luck in Texas.

Dr. Michelle Romeo - Let me thank you for serving this country again for many years and further bringing your restorative knowledge with you from the US Navy and sharing it with us. You have been such a great addition to our department, and it has been very pleasant working alongside you. 
Dr. James Polous - It is very motivating to see an individual as dedicated as you. Coming straight out of dental school, you are an extremely talented clinician and your transition to the endodontic program has been seamless.

Dr. Michael Tran - "We are what we repeatedly do. Excellence, then, is not an act, but a habit." I have never seen someone as meticulous and as detail oriented as you. I have observed and admired how you practice endodontics at the highest level. I feel so fortunate for having the opportunity to get to know you and to learn from you how to put in the best of my abilities every day. 


\section{Table of Contents}

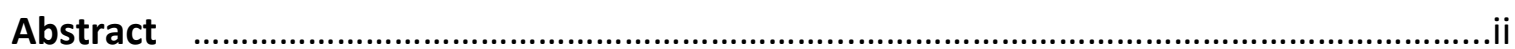

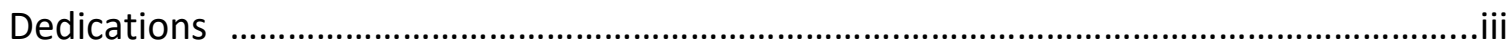

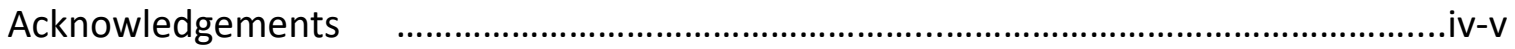

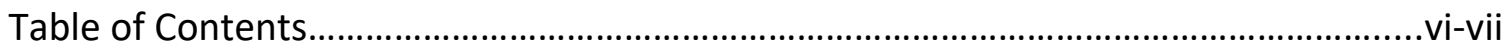

List of Tables

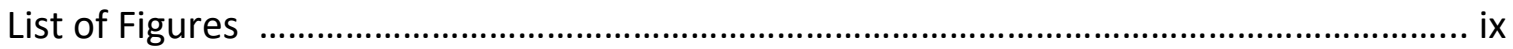

List of Symbols, Abbreviations or Nomenclature...............................................................

\section{Chapter 1}

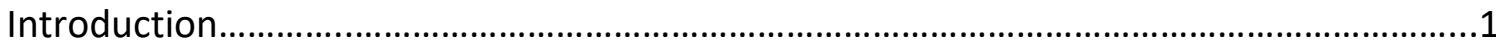

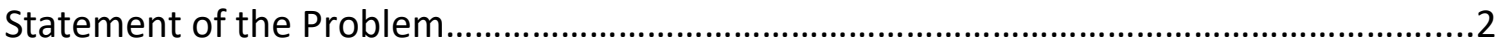

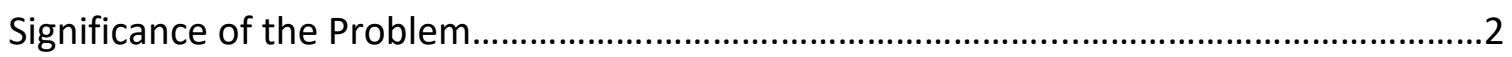

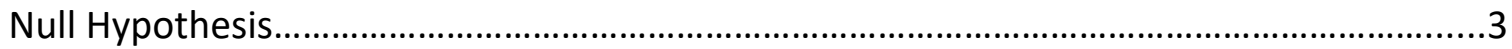

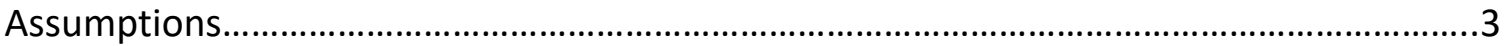

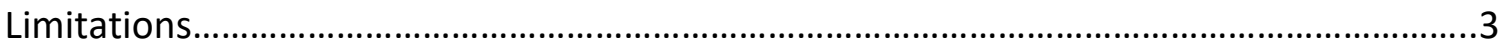

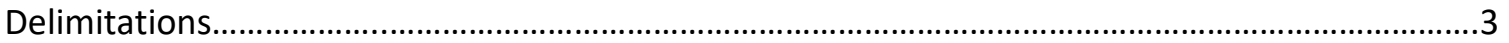

Chapter 2

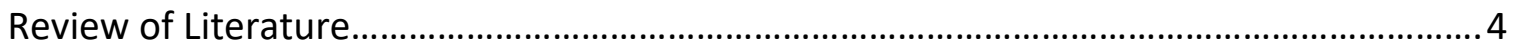

\section{Chapter 3}

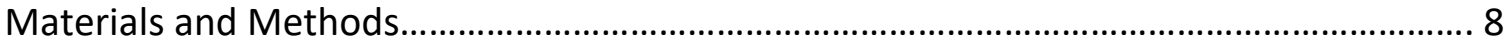

\section{Chapter 4}

Results. 
Chapter 5

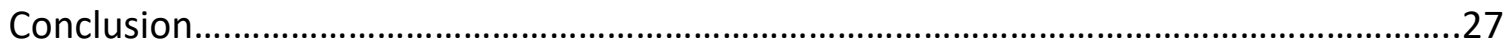

Works Cited 


\section{List of Tables}

Table 1. File sizes and tapers at different cross-sectional location.................................. 11

Table 2. Material Property of the Investigated Materials....................................................14

Table 3. Force Distribution over Surface Area..................................................................18

Table 4. Scenario of One Second Chewing Cycle...........................................................18 


\section{List of Figures}

Figure 1. Original Scanned tooth geometry in . stl format.................................................

Figure 2. The wrapped version of the original tooth model...............................................

Figure 3. The final reduced CAD with approximately twenty-five thousand surfaces......10

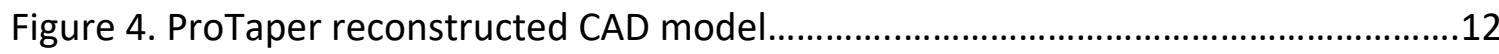

Figure 5. Vortex Blue reconstructed CAD model............................................................13

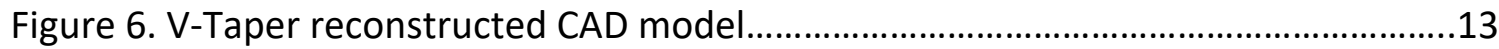

Figure 7. Control Group reconstructed CAD model........................................................14

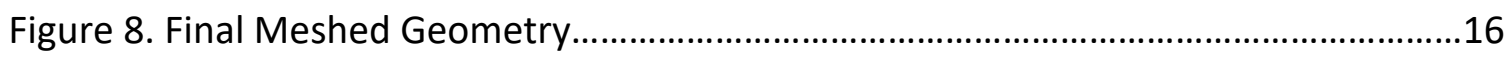

Figure 9. Normal chewing cycle and contact areas on Mx first molar...............................17

Figure 10. Schematic diagrams of the finite element models and location of the loads..17

Figure 11. Graph representing the pressure variation over one second chewing cycle...18

Figure 12. The distributions of von Mises stress and the maximum principal stress 2.5

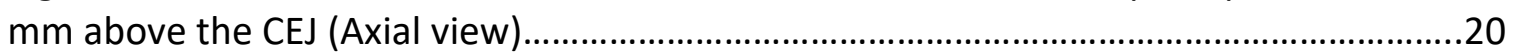

Figure 13. The distributions of von Mises stress and the maximum principal stress 0.3 $\mathrm{mm}$ above the CEJ (Axial view).

Figure 14. The distributions of von Mises stress and the maximum principal stress 0.3

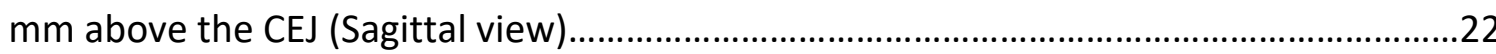

Figure15. The distributions of von Mises stress and the maximum principal stress 0.3 $\mathrm{mm}$ below the CEJ (Axial view).

Figure 16. The distributions of von Mises stress and the maximum principal stress 1.3 $\mathrm{mm}$ below the CEJ (Axial view) 


\section{List of Symbols, Abbreviations or Nomenclature}

American Association of Endodontists - AAE

Cemento enamel junction - CEJ

Finite Element Analysis - FEA

Nickle-Titanium alloy - NiTi

Newton $-\mathrm{N}$

Megapascal - Mpa

Mesiobuccal - MB

Distobuccal - DB

Palatal - P 


\section{Chapter 1 \\ Introduction}

Root fracture has been described as a major problem in dentistry and is the third most common cause of tooth loss after dental caries and periodontal disease (1). According to the 2012 edition of AAE (American Association of Endodontics) glossary of endodontic terms the definition of a cracked tooth is: "A phenomenon involving posterior teeth in which fractures usually involve the marginal ridges; primarily in minimally restored mandibular first and second molars; symptoms may vary but pain to chewing and thermal sensitivity are common. "There are however, a few problems with this definition. First, a cracked tooth is recognized by ENDODONTICS: Colleagues for Excellence as a finding only and not a phenomenon and this definition did not differentiate a crack from a fracture. In addition, this definition specified the location and type of teeth, which has become a significant limiting factor in this classification. As a result, the 2015 edition of AAE glossary of endodontic terms defines a cracked tooth as "A thin surface disruption of enamel and dentin, and possibly cementum, of unknown depth or extension" (no separation). A root fracture is defined as "A fracture that exists or extends into the root, to include dentin, cementum, and possibly pulpal space, which may progress to or from the enamel" (separation)(2)(3).

Another phrase that is associated with fractured teeth is cracked tooth syndrome. This phrase usually refers to the fracture of tooth structure associated with pain upon chewing, grinding, or any lateral movements (4). However, using the term cracked tooth syndrome could be misleading. For example, the syndrome is defined as a number of symptoms occurring together as a specific disease, and crack is not a disease nor is it a pathological entity. A crack will eventually lead to subsequent diseases such as pulpitis, infection of the root canal system or periodontitis.

It is very important for a clinician to understand the biomechanics of a crack that could result in tooth fracture. Crack initiation could be the result of a defect in various parts of tooth structure such as a hole, a ledge, or a notch. After the initiation phase, a crack could propagate as the result of different driving forces such as tensile stress, compression or shear force or torque. This process is usually a fatigue process when a material is subjected to cycles of load (5).

Generally, teeth after root canal treatment would undergo significant amounts of coronal and radicular tissue loss due to multiple prior restorative treatments, endodontic access cavity preparation, and cleaning and shaping of the root canal system. As a result, tooth fracture remains one of the most common reasons for tooth loss and extraction after endodontic treatment (6). In order to minimize the weakening effects of endodontic treatment, unnecessary removal of tooth structure should be avoided, especially in pre-cervical dentin $(7,8)$. 
After the development of rotary file instrumentation, numerous companies have produced different file systems. All of these files have various shapes, sizes and crosssectional geometry and behave differently within the root canal system. Consequently, there are many studies which compare fracture strength of endodontically treated teeth using different rotary instrumentation (9-11). According to Clark and Khademi, precervical dentin is a very critical zone that should be protected by the operator, and the file system that is chosen by the clinician. This critical zone $(4 \mathrm{~mm}$ above and below the cemento enamel junction (CEJ)) is irreplaceable and the long term survival rate of the tooth is highly dependent on the amount of tooth structure left in this region (12).

Many of the previous studies testing fracture resistance of endodontically treated teeth have been done in-vitro. However, the standardization of human extracted teeth and the limited sample size is a major obstacle using in vitro studies (11). In this study, FEA (Finite Element Analysis) is used in order to gain a better understanding of the effects of the cleaning and shaping process during endodontic treatment. FEA is an engineering method that analyses a very complex structure given the properties of the material used in that particular structure. The use of FEA would aid in understanding different factors contributing to initiation and propagation of cracks and fractures in root canal treated teeth. According to Rundquist, during the masticatory functions, the stress at the cervical region of the tooth increases as the taper of the files increases (13). In this study, three different commonly used file systems are compared that have significantly different diameter near the handle of the file. V-Taper (SS White), Vortex Blue (Dentsply Tulsa Dental Specialties, Johnson City, TN), and ProTaper (Dentsply Tulsa Dental Specialties, Johnson City, TN) are the files compared in this study.

The aim of this study is to compare the effect of three rotary file systems (VTaper, ProTaper, Vortex Blue) with different tapers on fracture resistance of endodontically treated teeth in the presence of various static and dynamic forces applied to different parts of the crown.

\section{Statement of the Problem}

Of three endodontic rotary file systems available in the market, which product is least likely to increase fracture resistance of endodontically treated teeth? Is there a statistically significant difference between these rotary instruments regarding the stress distribution on different parts of the crown and root structure?

\section{Significance of the Problem}

Cracks and fractures are a major problem in endodontically treated teeth and it has been recognized as the third leading cause of tooth loss in industrialized nations (5). The thickness of enamel is the greatest near cusp tips; however, this thickness decreases as it gets closer to the CEJ. This fact makes teeth most vulnerable at the CEJ level against 
lateral and occlusal forces. The findings of this study could potentially aid in determining if greater tapered rotary instruments have a significant effect on weakening teeth at cervical region.

\section{Null Hypothesis}

The null hypothesis states that there are no statistically significant differences in fracture resistance between the tested rotary instruments: V-Taper (SS White), Vortex Blue (Dentsply Tulsa Dental Specialties, Johnson City, TN), ProTaper (Dentsply Tulsa Dental Specialties, Johnson City, TN). Further, there is no significant difference in the accuracy of measuring fracture resistance of endodontically treated human teeth when comparing the universal testing machine method to the Finite Element Analysis method.

\section{Assumptions}

1. The Finite Element Analysis method of testing the fracture resistance of endodontically treated human teeth can accurately measure, analyze, and compare all the forces applied to a crown.

2. Each material was presumed to be homogeneous, isotropic, and linear elastic;

3. There was perfect bonding between each component.

4. There was no flaw in the initial model.

5. There were rigid constraints on the base and lateral surfaces of the alveolar bone. The material properties were referenced from the literature and are listed in Table 2.

\section{Limitations}

1. This was an in vitro experiment and the results may or may not replicate the clinical environment.

2. Operator error may have occurred during the experimentation process.

3. The forces applied on tooth structures are usually dynamic and multifactorial and they have been simplified in order to compare the experimental groups and analyze all the forces accurately.

\section{Delimitations}

1. Fracture resistance of all experimental groups and the control group were, tested using ANSYS software.

2. All experimental groups were prepared by a FEA specialist.

3. The 3 most currently utilized rotary instruments were selected for this experiment. 


\section{Chapter 2 \\ Review of Literature}

History of Rotary Instrumentation:

The father of modern dentistry, Pierre Fauchard, described the original root canal instrumentat as a small pin for pulpal extirpation. Later, Dr. Edwin Maynard introduced a four sided broach to remove the contents of the nerve canal space (14). In 1889, William H. Rollins introduced the first rotary handpiece. Nearly four decades later in 1928 the Cursor filling contra-angle was developed by an Austrian company called W\&H. In 1958 the Racer handpiece was introduced in Europe by W\&H. The new era of rotary instrumentation began in 1984 by Canal Finder System. Today, many companies produce a variety of Nickle-Titanium alloy (NiTi) rotary instruments, which allows clinicians to clean and shape the root canal system. The complexities of the root canal system have forced scientists to develop instruments that are capable of negotiating very narrow and complex anatomies of teeth (15).

NiTi was developed originally in the Naval Ordnance Laboratory in 1963, which was then known as Nitinol (16). The first use of NiTi was in orthodontic wires due to the properties of this alloy. Later, Walia introduced the first handheld NiTi endodontic instruments (17). Before introduction of NiTi instruments, endodontic files were made from carbon steel or stainless steel. These materials were extremely stiff and brittle, and they caused canal transportation, strip perforation, zipping perforation and ledge formation. They also broke very easily due to lack of elasticity and flexibility (18). Since 1990, NiTi rotary instruments have undergone tremendous advancements. These improvements modified the file designs, shapes, sizes, and metallurgy of the instruments. These advancements have resulted in instruments with improved cyclic fatigue, torsional stress, cleaning and shaping processes (19).

There have been five generations of $\mathrm{NiTi}$ instruments. The first generation came about in the mid-1990s. Profile-Dentsply (1993), Quantec-SybronEndo (1996), and GT system-Dentsply (1998) are some examples of these files. They had a fixed 0.04 or 0.06 taper with a passive cutting edge and were able to clean and shape the root canal system after multiple passes (20). The second generation was introduced in the market in 2001 with active cutting edges. These instruments were more effective in cleaning and shaping the root canal system and successful negotiation of calcified canals. ProTaper Universal-Dentsply, K3-SybronEndo, Mtwo-VDW, Hero Shaper-Micro-Mega, I Race, and I Race Plus-FKG Dentaire are examples of these files. Some studies showed that a significant amount of canal transportation occurred during utilization of some rotary instruments such as ProTaper files (9). 
The third generation of endodontic rotary instruments came with advancements in metallurgy of the NiTi alloy. Nickel-Titanium alloy, unlike most metals has the ability to deform up to $8 \%$ beyond the yield strength and still returned to its original shape after removal of stress load. The special properties of this alloy are related to martensitic transformation. Stress load or temperature reduction results in movements of atoms into a new more stable crystalline form called an austenite phase. This phase change is reversible and allows the NiTi instruments to recover their original shape and form (21). As a result, manufacturers treated NiTi instruments with new heating and cooling procedures and created $\mathrm{M}$-wire and $\mathrm{R}$-phase technologies to reduce cyclic fatigues and decrease the risks of breakage (22). A few examples of the third-generation rotary instruments are K3 XF Files-SybronEndo, Profile GTX Series-Dentsply, controlled memory (CM) Files (HyFlex CM)-Coltene, and Vortex Blue (Dentsply Tulsa).

The fourth-generation rotary instruments began with the introduction of reciprocating NiTi rotary instruments. Wave One-Dentsply, self-adjusting file (SAF)ReDent Nova, and Reciproc-VDW are some of the most well-known files with reciprocating capabilities. These files are very efficient in reducing bacterial load. However, some studies have shown that the amounts of extruded debris into the periapex after their use is significantly higher as compared to files with full rotational motion (23).

Most recently, the fifth generation of rotary instruments introduced offset design cross sectional shape files. Examples of these files are HyFlex/electrical discharge machining (EDM)-Coltene, Revo-S-Micro-Mega, One Shape Micro-Mega, and ProTaper Next-Dentsply. Because of this special design, the files have less screwing effect during use and therefore, potentially less risks of separation (24).

Apical Diameter and Taper Size:

The long-term outcome of endodontic treatment is predicated on success of both root canal treatment and restorative treatment. The root canal procedure goal is to address and resolve apical periodontitis by removal of bacteria from the root canal system (25). Siquiera et al has shown that instrumentation alone without the use of any chemical disinfectant is $90 \%$ effective for the removal of bacteria in root canals (26). Furthermore, by adding chemical irrigation solution such as EDTA and sodium hypochlorite along with mechanical instrumentation, a significant reduction of biofilm in the canal system is achievable (27). Various studies argue that larger size instrumentation would allow better disinfection of the root canal system (28). However, some studies show that apical enlargement did not have any significant effect on reduction of bacterial load and biofilms in comparison with smaller file size preparations (29). Endodontic files have been designed by various manufacturers in order to develop the most effective way to debride and clean the root canal system. However, due to the variety of files available, selecting an appropriate file type and design can be challenging for clinicians wanting to achieve a successful patient centered outcome. The files used in 
this study have the same tip size (0.25), but the taper of these files is different. V-Taper file measured from D1 to D4 is an $0.06 \mathrm{~mm}$ Taper. From D5 to D8 it reduces to an $.03 \mathrm{~mm}$ Taper. From D9 to D12 it reduces in size again to an $0.02 \mathrm{~mm}$ taper. And from D13 to D16 there is no taper. The Vortex Blue file is a constant 0.04 taper starting from D0 to D16. The ProTaper file is a variable taper file, with an $0.08 \mathrm{~mm}$ taper at the first $3 \mathrm{~mm}$. Subsequently the taper is 0.06 from D3 to D6 and from D6 to D16 the taper is 0.055 .

Root Fractures and RCT:

It is important to have an understanding of the mechanism of fracture of endodontically treated human teeth as a result of chewing forces. Cracked and fractured teeth can be major problem in endodontically treated teeth, and it is recognized as the third leading cause of tooth loss in industrialized nations (5). Gher et al, found that vertical root fractures are usually associated with endodontically treated teeth and the incident of occurrence found as high as $67 \%$ in molar teeth (30). Meister et al, established that 84.38 percent of fractures are a result of forces of lateral condensation during root canal therapy (31). In addition to root canal therapy, a variety of restorative treatments also generate added stress on tooth structure, which could make teeth more susceptible to fracture.

The typical signs and symptoms associated with teeth that have vertical root fracture are percussion sensitivity, fenestration or dehiscence in the alveolar bone, swelling, sinus tract, hot and cold sensitivity. The main issue arises because many of these signs and symptoms are similar to teeth that have only pulpal and periapical diseases without having a fracture (32). This fact makes diagnosis of teeth with vertical root fracture extremely challenging. In a survey by Tamse et al, only one-third of the 92 fractured teeth were correctly diagnosed by clinicians participating in this study (33).

Advancements in rotary instruments have allowed clinicians to clean and shape the root canal systems in a much more effective manner. The speed of instrumentation has increased, and the dentin removal capabilities of rotary instruments has significantly improved. There have been many studies with conflicting results that compared the effect of instrumentation on dentinal fracture resistant abilities. Cheron et al, found that there are no significant nanomechanical changes to radicular intertubular dentin in root canal treated teeth compared to non-treated teeth (34). However, in a recent study Yan et al found that the strength of dentin from root canal treated teeth decreases after instrumentation (8).

Enamel is the hardest part of the human body. It is approximately $96 \%$ mineralized with small amount of organic substance and water. The mineral portion of enamel is organized in a very structured manner reffered to as enamel rods or prisms, which extend to the dentin-enamel junction (DEJ). The thickness of enamel is the greatest near cusp tips. This thickness decreases as it gets closer to the CEJ. This fact makes teeth most vulnerable at the CEJ level against lateral and occlusal forces (35). 
Therefore, it is ultimately the clinician's responsibility to be aware of the overall effect of root canal treatment and be considerate of tooth structure at CEJ level during the access and instrumentation stages of endodontic treatment.

In addition to the size of rotary files, the amount of taper of these files plays a significant role in the overall cleaning and shaping process. Taper is the amount of file diameter that increases along the length of the file from the tip to the handle. For instance, a size 30 file with a 0.04 taper would be $0.34 \mathrm{~mm}$ in diameter $1 \mathrm{~mm}$ from the tip. Also, some manufacturers produce rotary files with variable taper along the length of the files. In addition to taper, the cross-sectional shape and maximum flute diameter of rotary files play an important role in the overall performance of the file and the final shapes of the canal after complete instrumentation (36).

There have been many studies that evaluated the effect of access cavity design and taper preparation of root canals on endodontically treated teeth fracture resistance (11,37-39). The results of these studies are inconsistent. As a result, this topic remains open to discussion and further investigation. It is important to notice many of these studies are in vitro studies. There are many common problems in working with extracted human teeth. First and foremost, standardization is a major limitation of these types of studies between experimental groups. When working with extracted human teeth it is practically impossible to find identical teeth in similar conditions to distribute between the experimental groups. In addition, there may have been some thermal and mechanical damage that was inadvertently created during preparation of the specimens. There could also have been significant damage during extraction procedures. Patient age, chewing and bruxing habits, and previous restorative treatments also create microfractures that are essentially impossible to detect with the naked eye, which would affect the accuracy and reliability of these studies.

As a result, methodologic limitations concerning both the standardization and randomization of the sample combined with the instrumentation and experimental techniques used have produced a variety of results. To eliminate these problems this study uses FEA to examine the influence of instrument taper on the fracture resistance of endodontically treated teeth. The FEA is a computerized procedure that would create computerized models of real-life structures. The FEA then has the abilities to analyze various structural properties of any material under different amounts of stress and load. The FEA has the ability to remodel the pattern of stress distribution of very complex structure and uncover the biomechanical properties of these materials (40). 


\section{Chapter 3 \\ Materials and Methods}

CAD Preparation:

In this study, a 3D printed acrylic maxillary first molars from Dental Engineering Laboratories LLC DBA DELabs (True Tooth) were used as the prototype of the research model. The real tooth geometry is complex and contains many details. In order to obtain reliable results from FEA, the first step is to prepare the CAD geometry of the tooth. The tooth was scanned using a micro-computed tomographic scanner (SkyScan1176; Bruker mi- croCT, Kontich, Belgium). The scanning parameters were as follows: $70 \mathrm{kV}, 100 \mathrm{~mA}$, and $100-\mathrm{mm}$ slice thickness. The output of the scanner machine was imported into ANSYS SpaceClaim software as a .stl file format. The figure below shows the original geometry without any modifications.

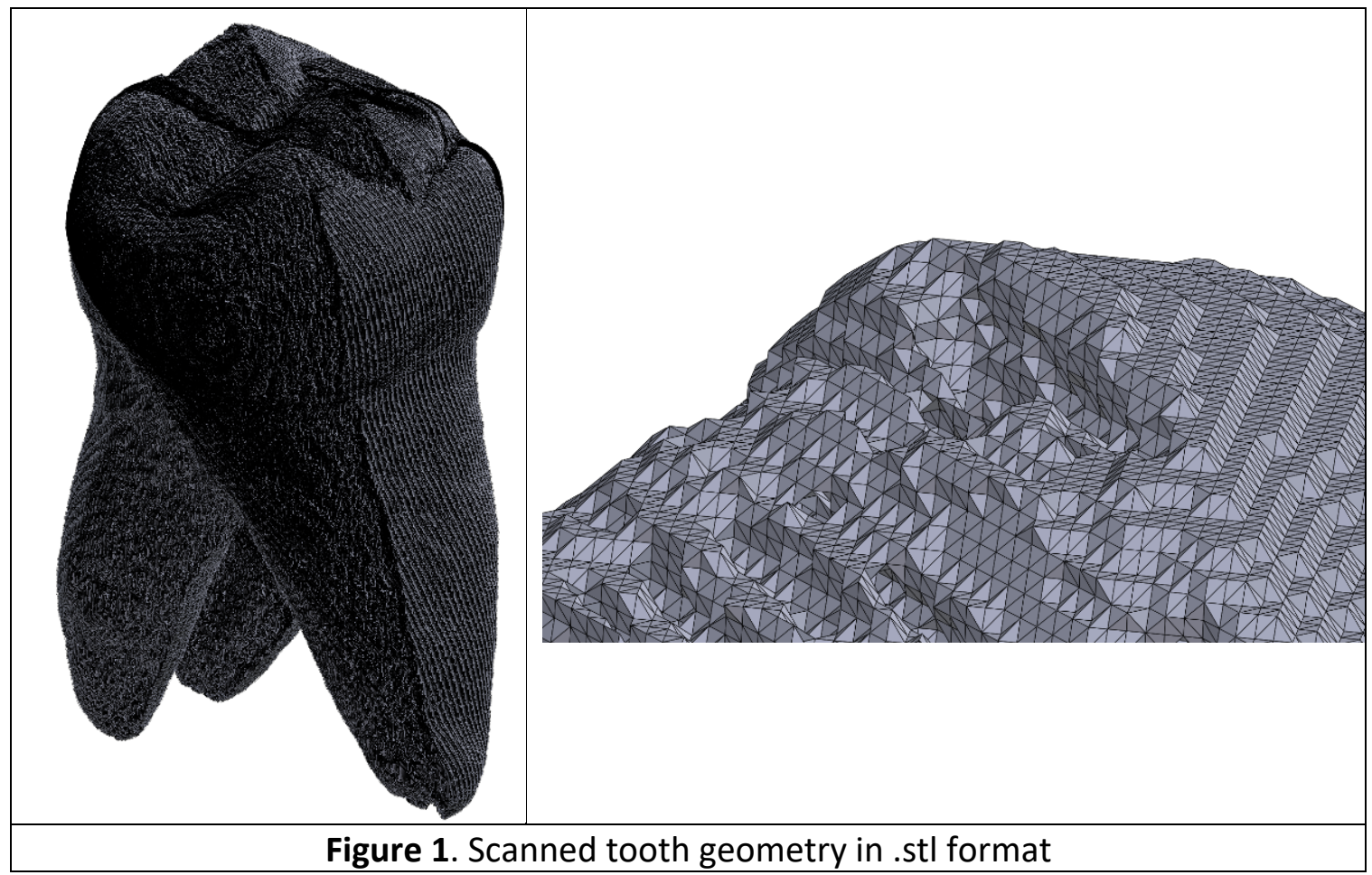

As can be seen in Figure 1, the original CAD has all of the details of the original tooth surfaces, however, the surfaces and edges form very sharp corners. Having sharp edges in FEA would result in undesirable stress concentration points that are not realistic. This type of geometry is not suitable for FEA and must be converted to solid bodies with more curved and rounded surfaces. Also, the primary CAD file was very large, which made it difficult to make any modifications in the ANSYS software and to 
solve the geometry using FEA and obtain results. Another purpose of the CAD conversion was to reduce the file size to be readable in FEA software.

To reduce the file size and modify the sharp corners, the wrapping option in the SpaceClaim was used. Using this option, the sharp corners were covered by a wrapping surface. As shown in Figure 2, the modified geometry contains all the details of the original geometry, but the number of small surfaces and edges have been reduced significantly. In addition, the sharp angles were replaced by smoother surfaces.

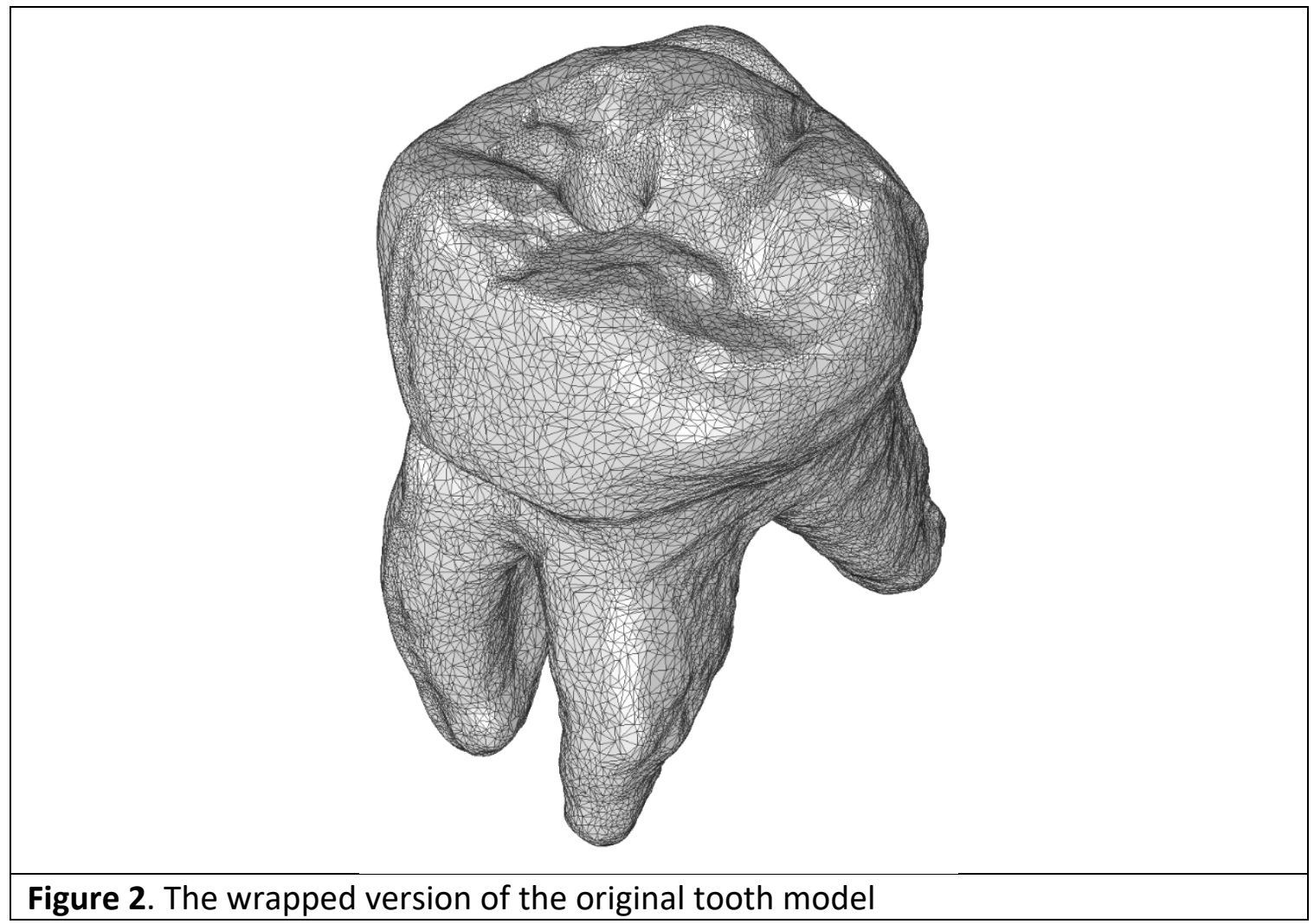

Although the number of faces was reduced after the first step, the model still contained over one million small surfaces. All these surfaces were irregular and unstructured. Therefore, the file size was further reduced, to create more structured and uniform equilateral triangles.

At this step, an option in the SpaceClaim was used in which the adjacent small surfaces with an angle larger than a threshold were combined into a single surface. In this case the reduce option was used three times with the angle threshold of sixty degrees. The angle threshold was selected after a few trial runs, which showed good size reduction rate and kept all the small features of the original CAD. Figure 3 shows the final reduced CAD that contains less than twenty-five thousand surfaces. This number of surfaces was within an acceptable range for the FEA solver. 


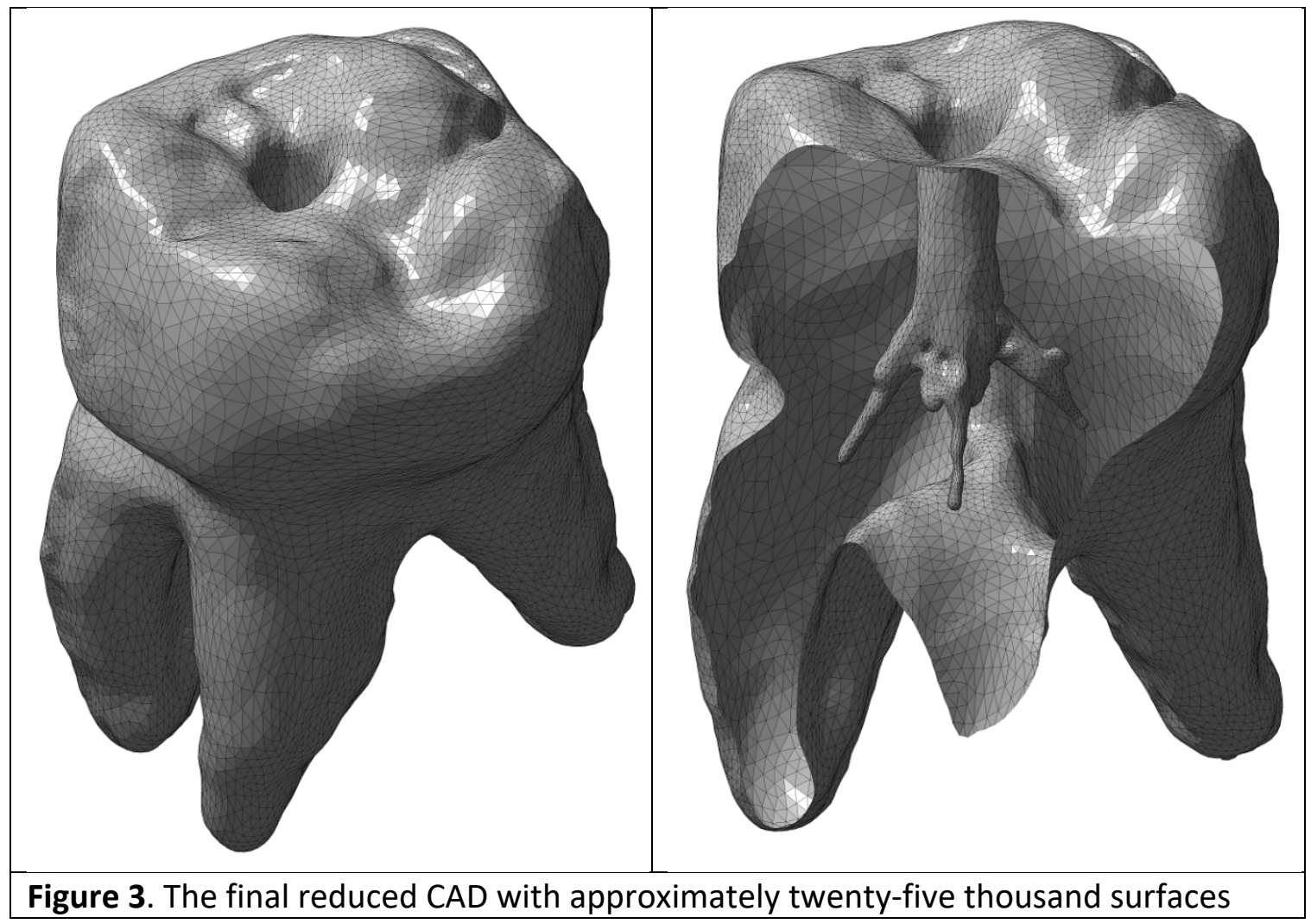

Figure 3. The final reduced CAD with approximately twenty-five thousand surfaces

After modifying the original geometry, the three experimental groups and one control group were created. Group one was ProTaper, group two was Vortex Blue and group three was V-Taper. The file measurements from D16 to D0 are provided in Table 1. 
Table 1. File sizes and tapers at different cross-sectional location

\begin{tabular}{|l|r|r|r|}
\hline \multirow{2}{*}{$\begin{array}{c}\text { Cross- } \\
\text { Lection }\end{array}$} & \multicolumn{3}{|c|}{ File } \\
\cline { 2 - 4 } & $\begin{array}{l}\text { V- } \\
\text { taper }\end{array}$ & \multicolumn{1}{|l|}{$\begin{array}{l}\text { Vortex } \\
\text { Blue }\end{array}$} & \multicolumn{1}{l|}{$\begin{array}{l}\text { ProTaper } \\
\text { Gold }\end{array}$} \\
\hline D16 & 0.69 & 0.89 & 1.215 \\
\hline D15 & 0.69 & 0.85 & 1.16 \\
\hline D14 & 0.69 & 0.81 & 1.105 \\
\hline D13 & 0.69 & 0.77 & 1.05 \\
\hline D12 & 0.69 & 0.73 & 0.995 \\
\hline D11 & 0.67 & 0.69 & 0.94 \\
\hline D10 & 0.65 & 0.65 & 0.885 \\
\hline D9 & 0.63 & 0.61 & 0.83 \\
\hline D8 & 0.61 & 0.57 & 0.775 \\
\hline D7 & 0.58 & 0.53 & 0.72 \\
\hline D6 & 0.55 & 0.49 & 0.665 \\
\hline D5 & 0.52 & 0.45 & 0.61 \\
\hline D4 & 0.49 & 0.41 & 0.55 \\
\hline D3 & 0.43 & 0.37 & 0.49 \\
\hline D2 & 0.37 & 0.33 & 0.41 \\
\hline D1 & 0.31 & 0.29 & 0.33 \\
\hline Tip & 0.25 & 0.25 & 0.25 \\
\hline
\end{tabular}

The ANSYS Boolean operations were done in order to generate four different experimental CAD models. This operation was completed using a combination of three CAD software programs: Solidworks $\AA$, Design Modeler $\AA$, and Spaceclaim $\AA$. The first step was to prepare a conventional access with one-degree inward taper to the pulpal floor. Canals were then prepared and designed starting at the pulpal floor and extending to the apex. The apical foramina were enlarged to $0.3 \mathrm{~mm}$, and the working length was set at $0.5 \mathrm{~mm}$ coronal to the apical foramen. The average length of canals was approximately $16 \mathrm{~mm}$ so the maximum flute diameter of the canals reached to the level of the pulpal floor. There were four volumes in total. One for access cavity and four separate canals MB1, MB2, DB and P. After preparation of all the study groups the volumes were filled with appropriate materials. Canals were filled with Gutta Percha, and the access cavity was filled with composite for the experimental groups. For the control group all the canal spaces and the chamber remained empty and the access cavity was filled with dentin and $2 \mathrm{~mm}$ of enamel layer on top. 
Final 3D model of the control group and the three experimental group:

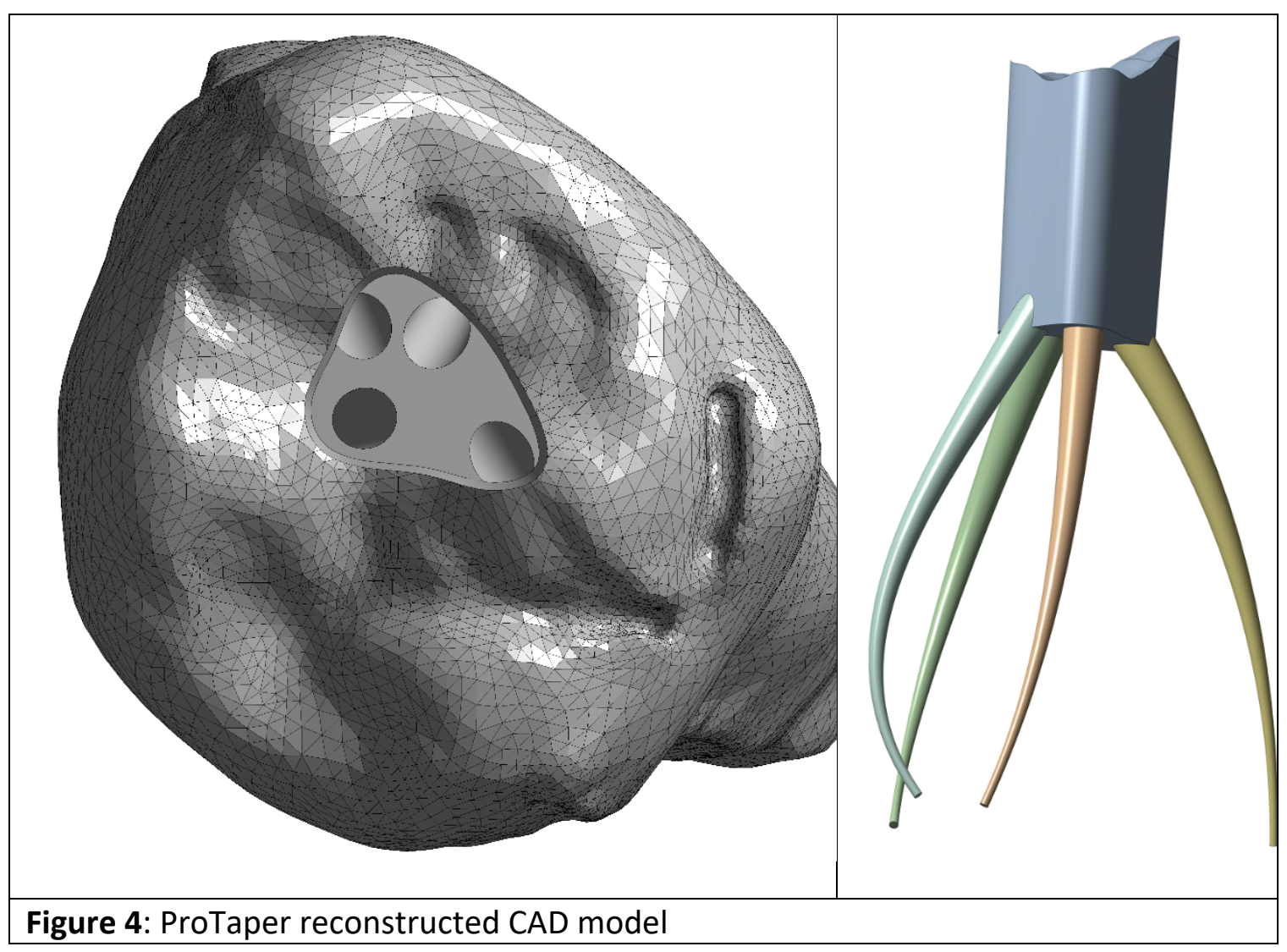



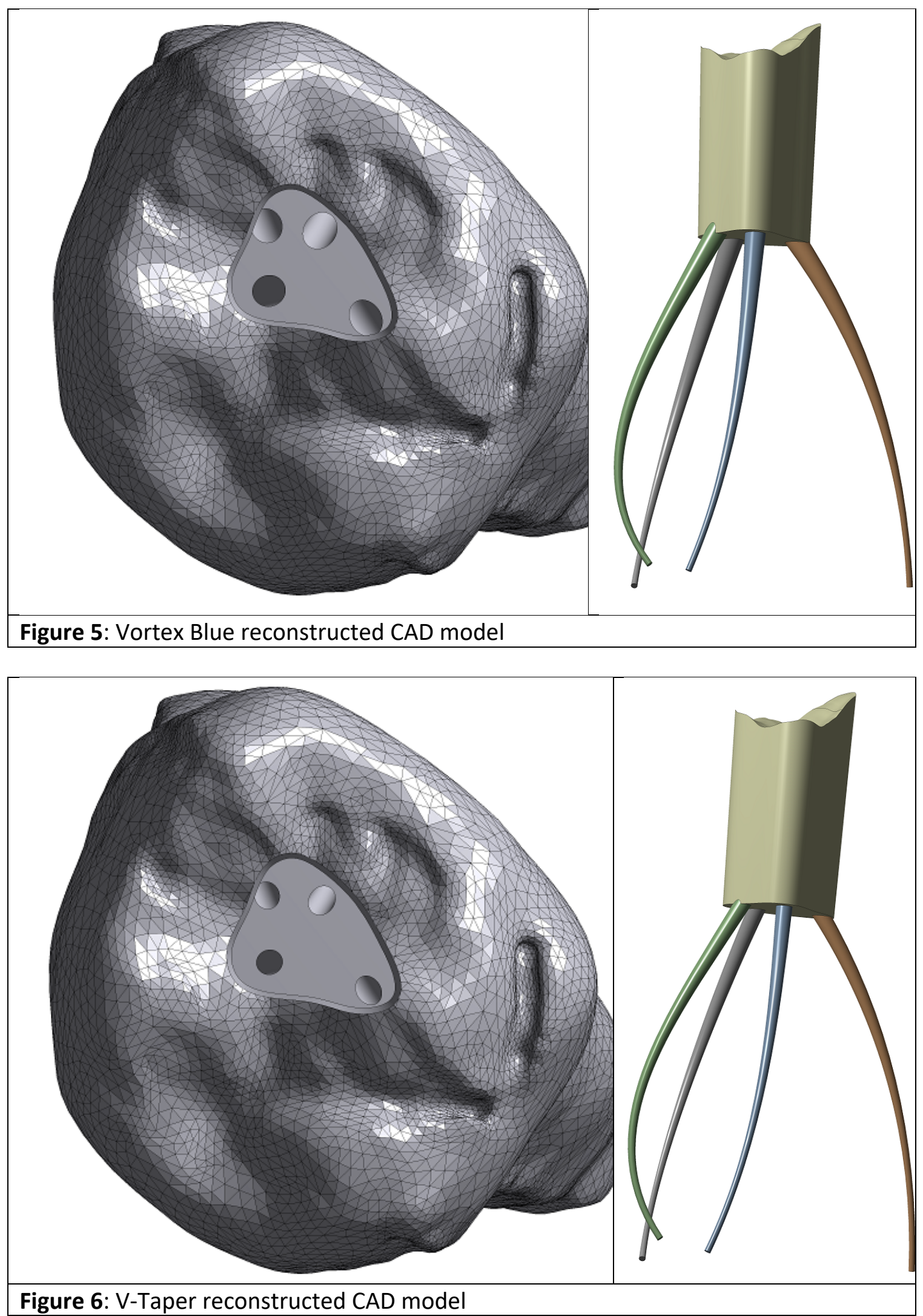


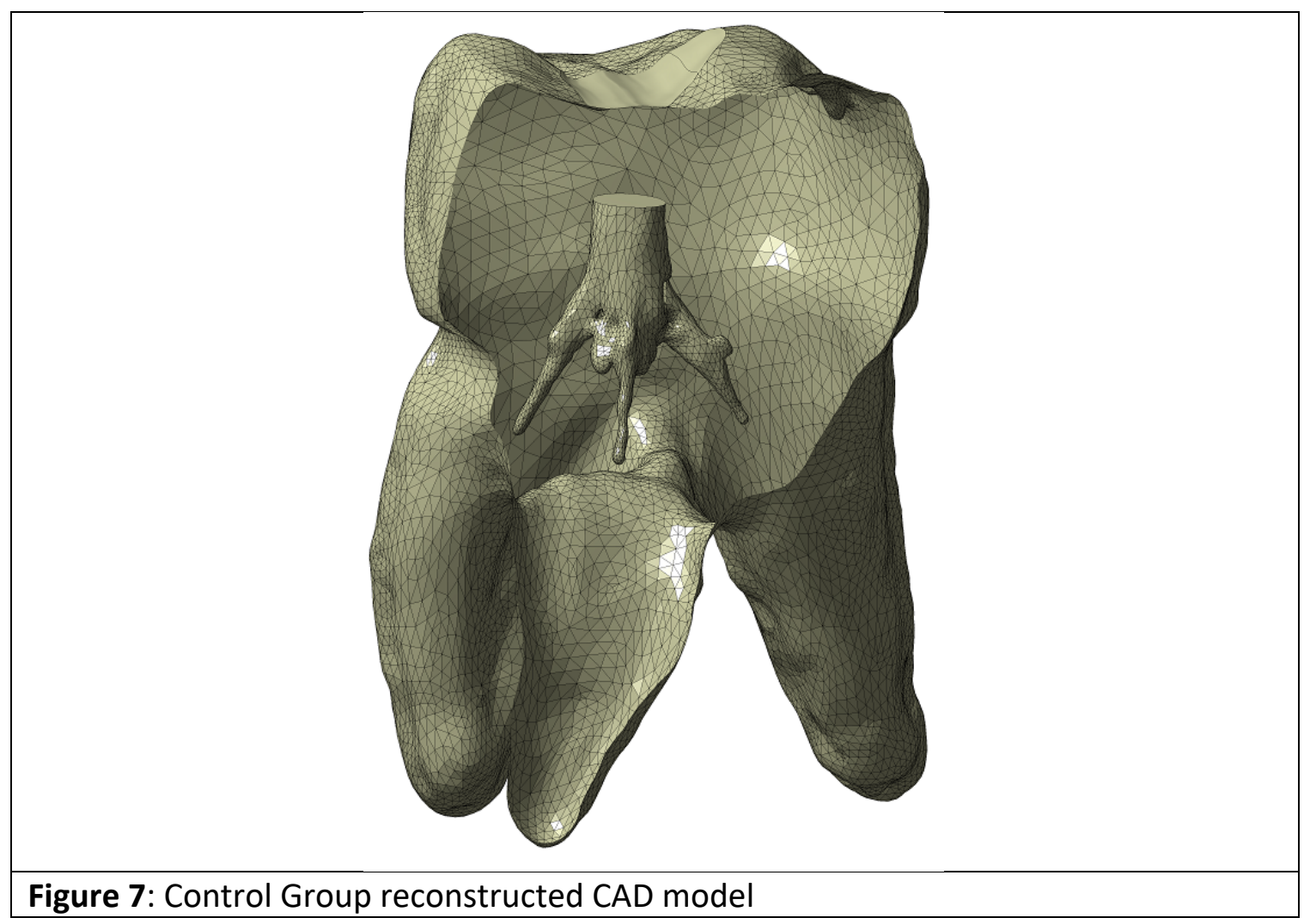

ANSYS Modeling:

FEA encompasses three steps: 1) geometry and material properties 2) geometry discretization (meshing) and 3) analysis setting (boundary conditions). Prior to meshing, it is required to define all the detectible geometries and indicate material properties for each of these volumes. Young modulus and Poisson ratio of all the materials are required for ANSYS software to recognize these volumes and the constituents that are contained within these individual spaces. Summarized in Table 2 is the information which was used to provide ANSYS with the ultimate loads that caused crack initiation.

\begin{tabular}{|l|l|l|}
\hline Material & Young Modulus (MPa) & Poisson Ratio \\
\hline Enamel & 84,100 & 0.30 \\
\hline Dentin & 18,600 & 0.31 \\
\hline Composite Resin & 7000 & 0.30 \\
\hline Gutta-Percha & 140 & 0.45 \\
\hline Periodontal Ligament & 68.9 & 0.45 \\
\hline Alveolar Bone & 13,700 & 0.3 \\
\hline
\end{tabular}

Table-2 : Material Property of the Investigated Materials (10) 
The next step in ANSYS modeling was geometry discretization or meshing. FEA divides the original geometry in smaller segments (piecewise polynomial interpolation) and calculates the relationship between displacement force and the stiffness in each of these subdivisions ( $\mathrm{F}$ [load] $=\mathrm{K}$ [stiffness] $\mathrm{X}$ X [displacement]). By connecting these elements, the field quantity becomes interpolated over the entire structure in piecewise fashion. As a result, the displacement of each individual segment of the original geometry would result in strain and ultimately stress concentration.

After calculation of displacement of each element in this model, the strain was calculated based on the stiffness of enamel, dentin, composite resin, Gutta-percha, and alveolar bone. Under a simple physics law called Hook's Law, strain is related to stress. In this study it was assumed that this geometry is homogenous, isotropic, and linear elastic. Based on these assumptions, all the materials behave the same under different directional forces, and the stress and strain were considered to have a linear relationship.

When a material is stretched it is under tensile stress. On the other hand, compressive stress occurs when the material is compressed. In general, most material (especially the brittle ones) have higher compressive strength than tensile strength. Due to the complexity of this geometry under any particular load, one element could be under tensile stress and the adjacent element could be undergoing a compressive stress. In addition, shear force presents as another component of an external force.

In order to determine when these materials would yield or fracture, Von Mises stress was calculated in each of these elements. Von Mises stress calculates and combines the normal forces with shear forces and produces an equivalent stress. This equivalent stress is then used to determine the materials ability to withstand any amount of force. In situations when the equivalent stress is higher than tensile strength, the material cannot withstand the load.

In this experiment meshing was completed using maximum size of $0.35 \mathrm{~mm}$ with tetrahedral geometry (each element has four sides). As shown in Figure 8 all the details were captured in meshing process with the total of 480,000 elements. 


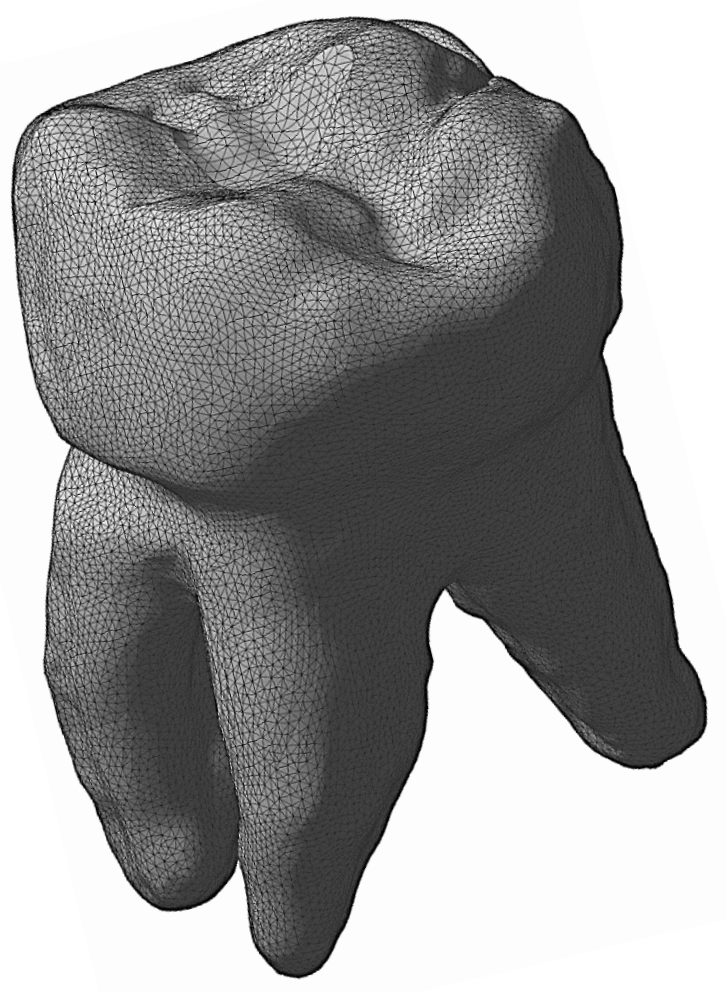

Figure 8: Final Meshed CAD Geometry

As stated previously the next step was analysis setting. In this step a fixed support and contact points were determined in order to obtain final results. In this model the fixed support was chosen to be below the CEJ. The total of seven contact points were identified on occlusal surfaces. The maximum bite force of a maxillary first molar is about $665 \mathrm{~N}$ (Newton) and might exceed $800 \mathrm{~N}$ during bruxism (10). In this study, the forces were applied in order to simulate the chewing cycle as illustrated in Figure 9. The buccal phase of chewing is also referred to as dental cycle-in, whereas dental cycle-out is called the lingual phase. Maximum possible force during chewing was used in this study. However, because the surface area of each contact point was different the forces were then distributed based on the surface area of each contact point. Therefore, the contact points with larger surface areas received higher amount of forces to disseminate equal pressure distribution. 


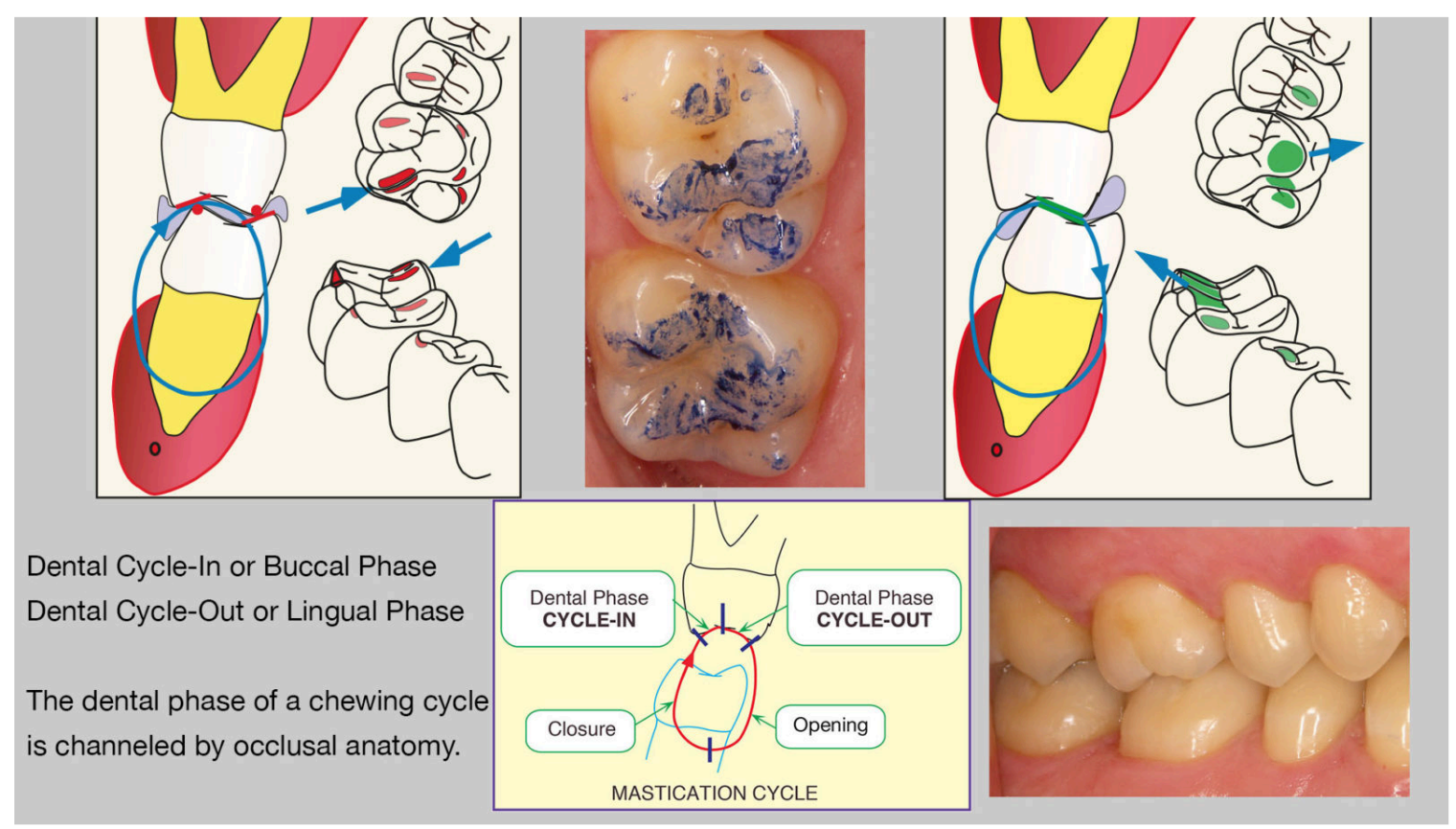

Figure 9: Normal chewing cycle and contact areas on maxillary first molar (41)

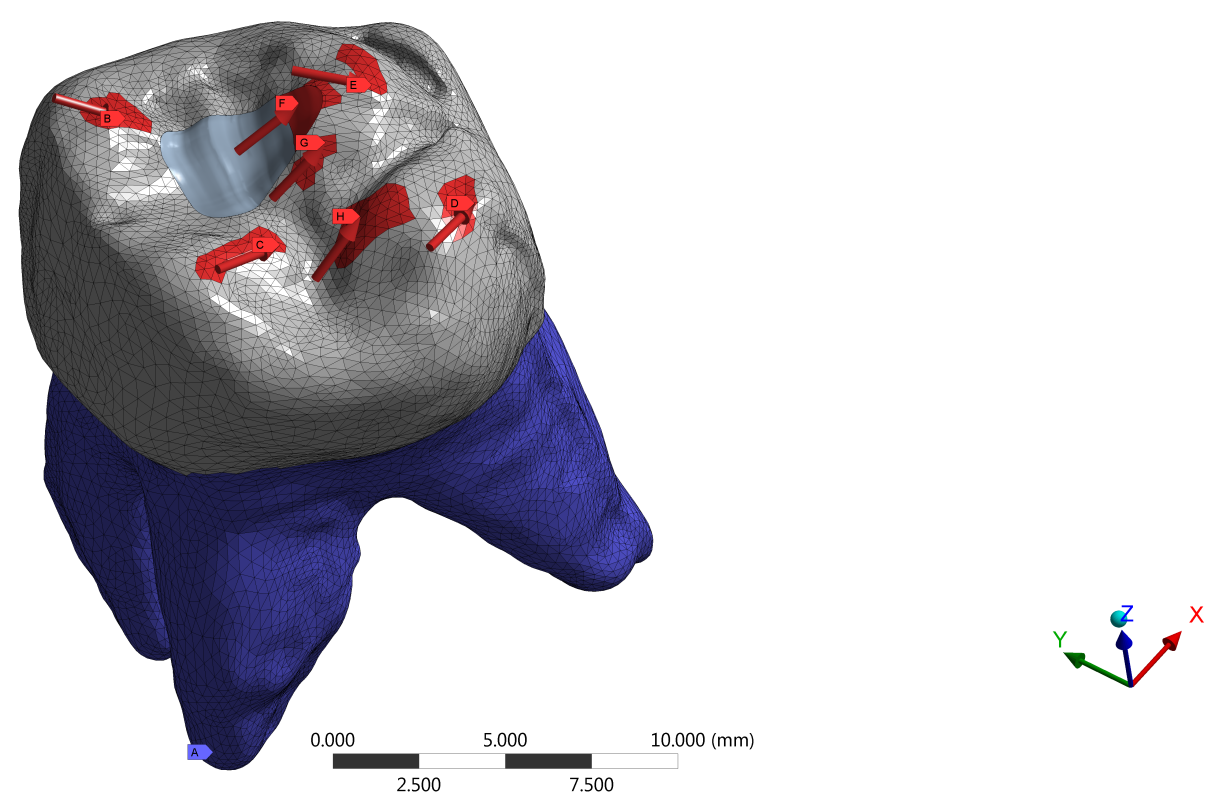

Figure 10: Schematic diagrams of the finite element models and load location. Red areas indicate contact points during chewing cycle. Purple illustrates the location of alveolar bone. 
In this study also a chewing cycle of one second was considered (half a second for in-cycle and half a second for out-cycle). During the in-cycle phase the forces started at zero and reached their maximum amount within 0.25 (seconds) and transitioned to out-cycle phase midway through the chewing cycle (Figure 11).

\begin{tabular}{|l|l|l|l|l|}
\hline Name & Surface Area (mm2) & Total Surface Area & Pressure & Force MPa \\
\hline I-1 & 2.7215 & 9.3884 & 85.21154 & 231.9032 \\
\hline I-2 & 2.6016 & & 85.21154 & 221.6863 \\
\hline I-3 & 1.9537 & & 85.21154 & 166.4778 \\
\hline I-4 & 2.1116 & & 85.21154 & 179.9327 \\
\hline O-1 & 2.8020 & 8.0256 & 99.68102 & 279.3062 \\
\hline O-2 & 1.1633 & & 99.68102 & 115.9589 \\
\hline O-3 & 4.0603 & & 99.68102 & 404.7348 \\
\hline
\end{tabular}

Table 3: Force Distribution over Surface Area

\begin{tabular}{|l|l|l|l|}
\hline Time & In Cycle (Force MPa) & Time & Out Cycle (Force MPa) \\
\hline 0 & 0 & 0.5 & 49.846 \\
\hline 0.25 & 85.21154 & 0.75 & 99.68102 \\
\hline 0.5 & 42.605 & 1 & 0 \\
\hline
\end{tabular}

Table 4: One Second Chewing Cycle Scenario

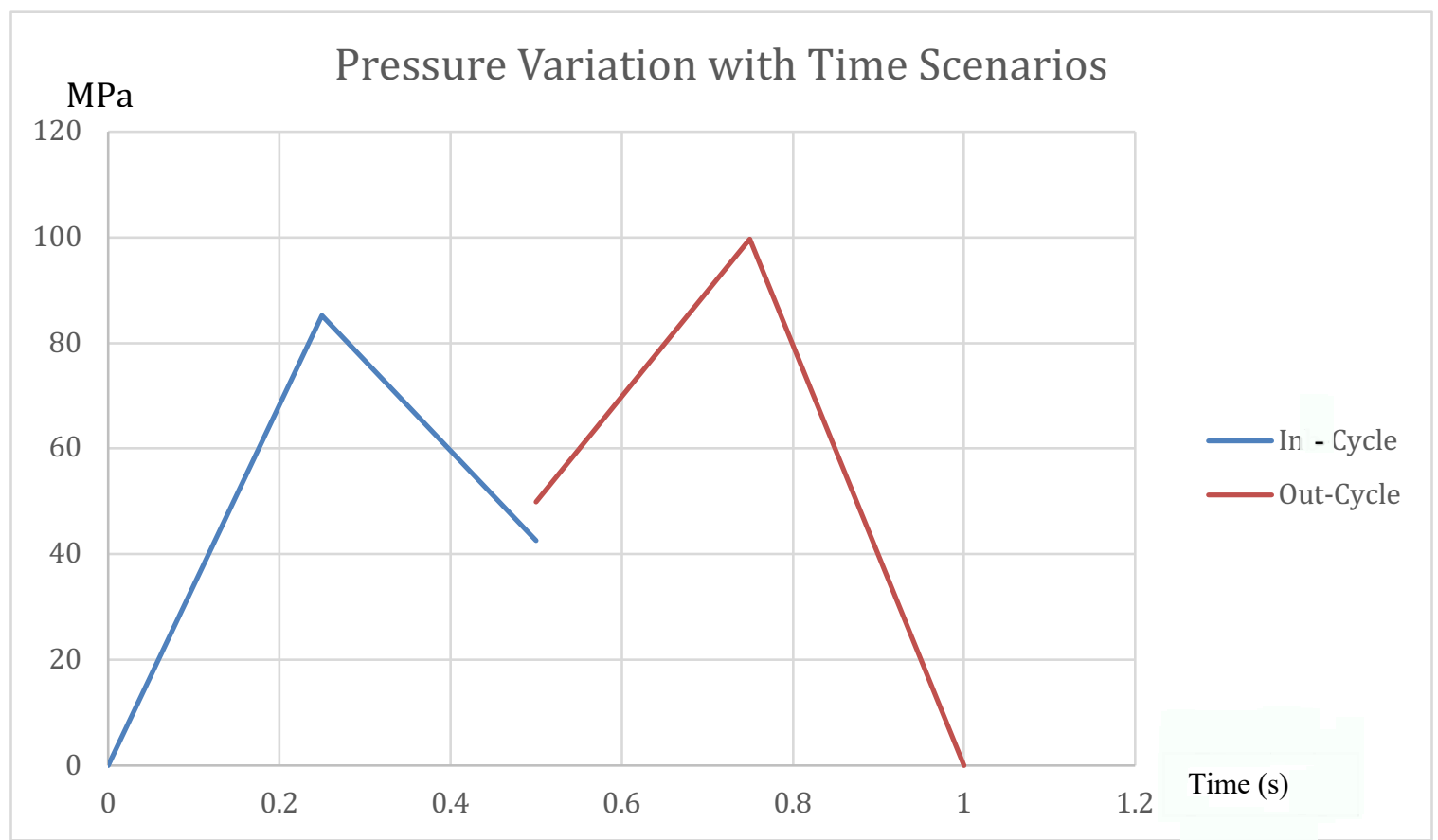

Figure 11: Graph representing the pressure variation Mpa over one second chewing cycle 


\section{Chapter 4}

\section{Results}

The Von Mises stress and maximum principal stress on the cervical region of maxillary first molar computer simulated model were computed and analyzed. In this study, the cervical region was considered a critical zone. The stress distribution of the chewing force was studied and analyzed in four separate horizontal cross sections of the cervical region. Three cross sections were located above the pulpal floor and one below the pulpal floor at the level of buccal furcation. Von Mises stress was concentrated the mostly around the CEJ level (Fig. 12-14). The highest Von Mises stress was observed in the ProTaper group, although V-Taper and Vortex Blue groups showed homogeneous stress distributions in the cervical regions as well.

The stress distributions of the maximum principal stress in the cervical region were analyzed. The ultimate loads that caused failure of dental material was considered to be $50 \mathrm{MPa}$ and any amount of stress higher than that was shown in red in all the experimental group, and it was considered detrimental to the tooth structure.

In all experimental groups, tensile stress was concentrated on the palatal side of the palatal root and the distal portion of the distobuccal root in the cross sections at the level of CEJ and the pulp chamber floor (Figure 13-14). However, the intensity of stressed areas differed among each experimental group. The control group had the least amount of stressed area in red followed by $\mathrm{V}$-Taper group, Vortex Blue and ProTaper. 
Figure 12-14: The distributions of von Mises stress and the maximum principal stress on the sections of the CEJ, the pulp chamber floor (PCF), and the root furcation (RF). Each color represents a range of stress values (in $\mathrm{MPa}$ ) corresponding to the scale. The areas in red and orange were the high stress concentration areas. Dark blue designates low stress concentration areas. A smaller stress concentration area was detected in the control group and V-Taper group $(\mathrm{J})$ compared with the ProTaper $(\mathrm{H})$ and Vortex Blue (I).

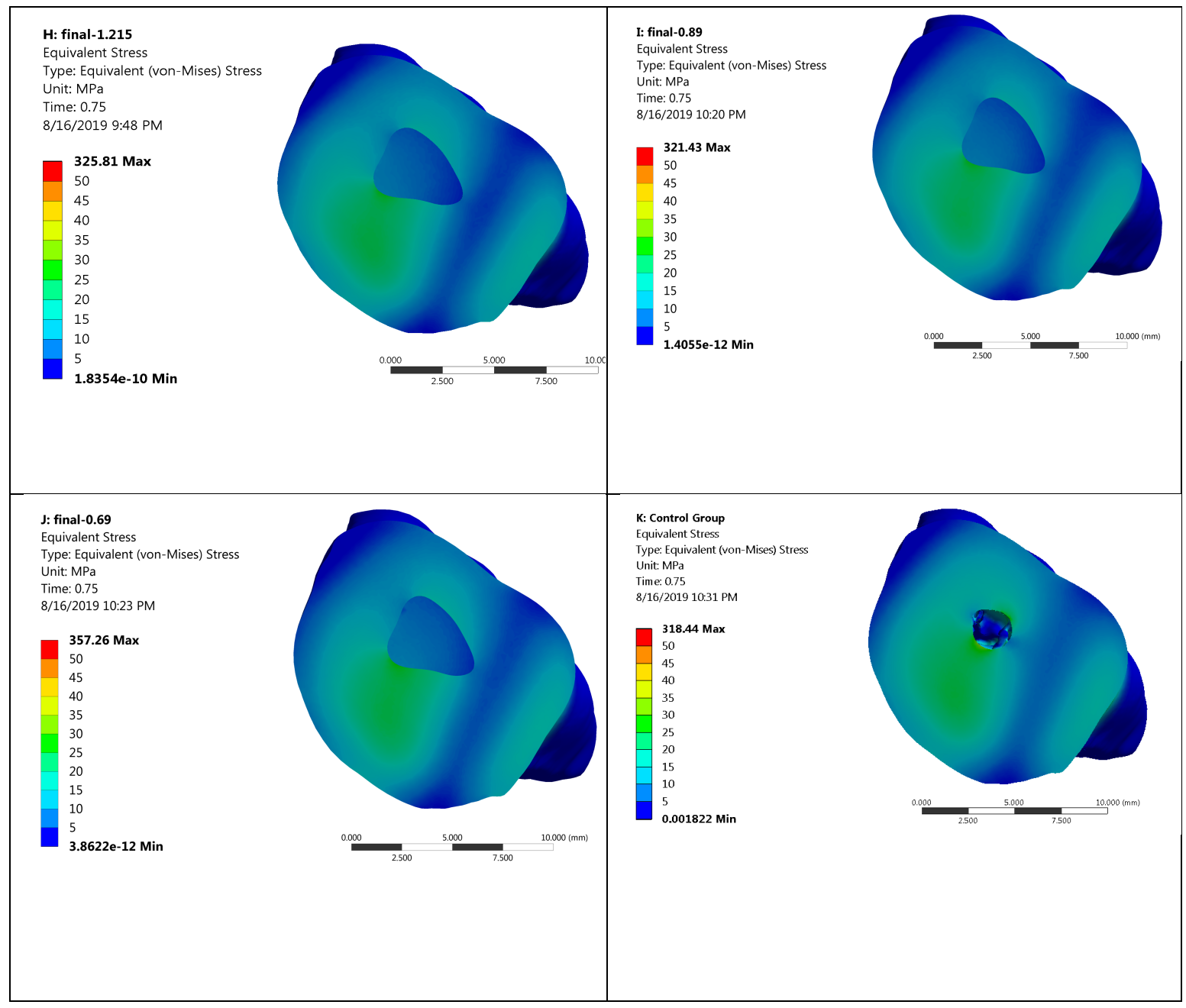

Figure 12: $2.5 \mathrm{~mm}$ above the CEJ (Axial view) 


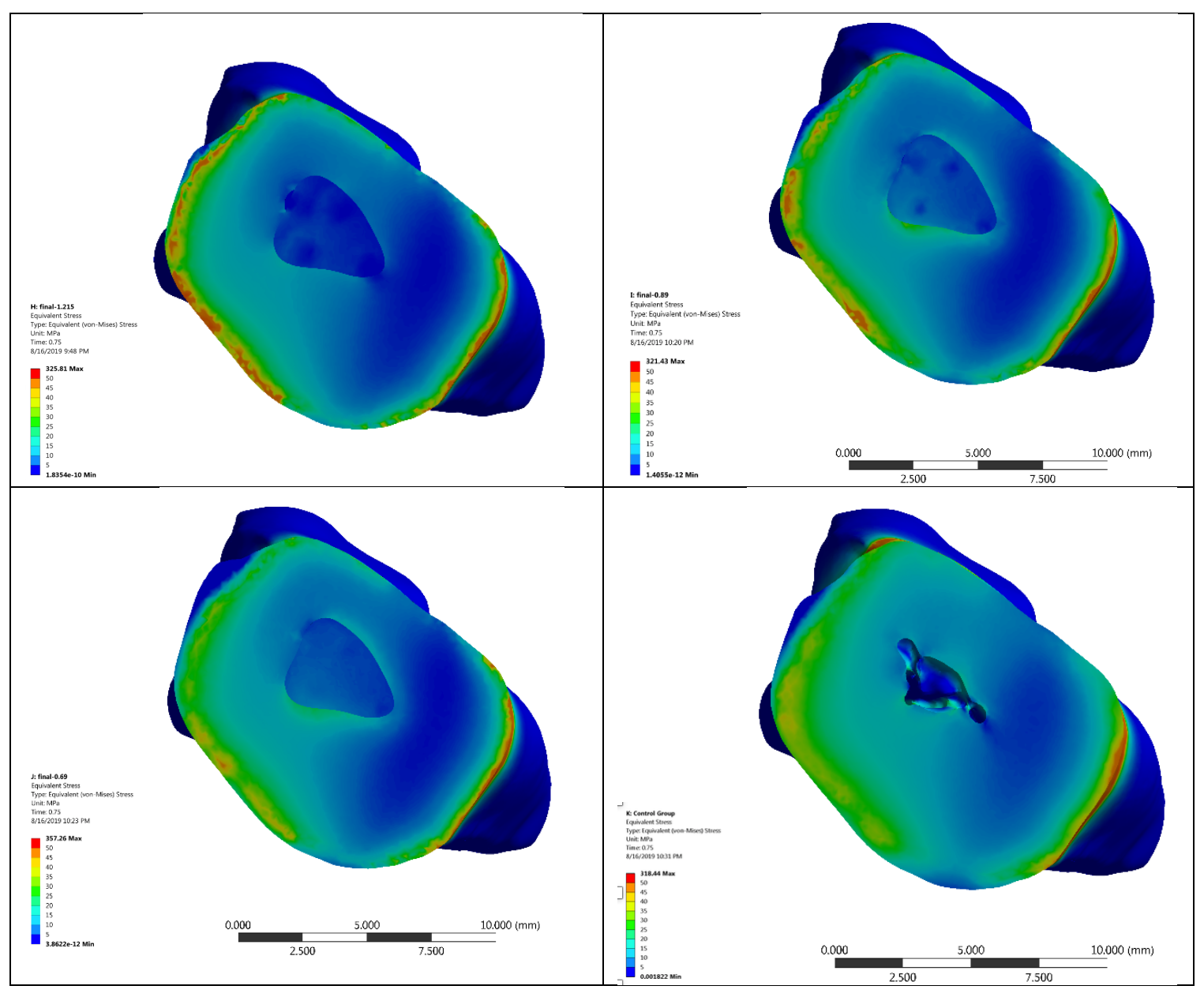

Figure 13: $0.3 \mathrm{~mm}$ above the CEJ (Axial View) 


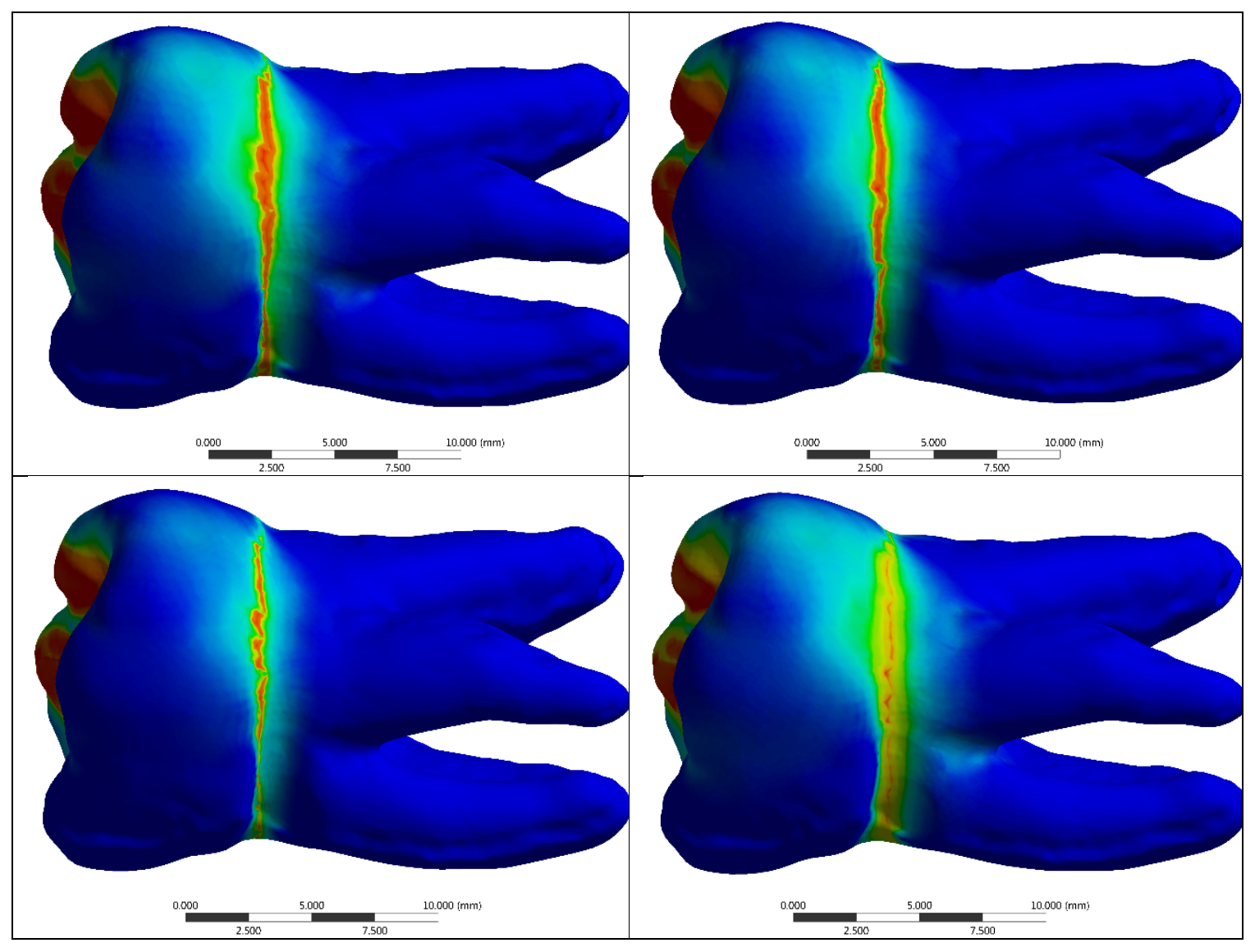

Figure 14: $0.3 \mathrm{~mm}$ above the CEJ (Sagittal View) 


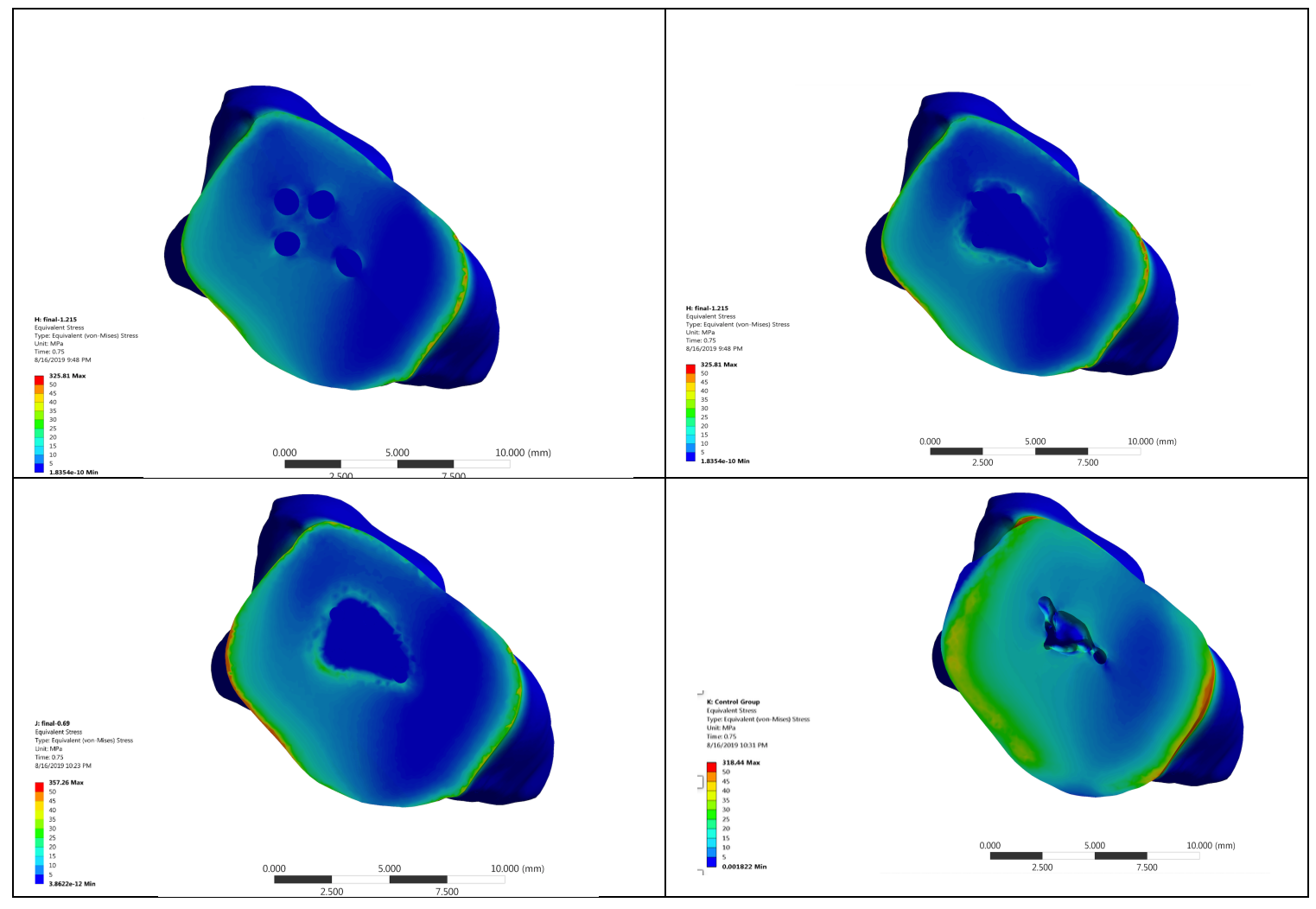

Figure 15: $0.3 \mathrm{~mm}$ below the CEJ (Axial view) 


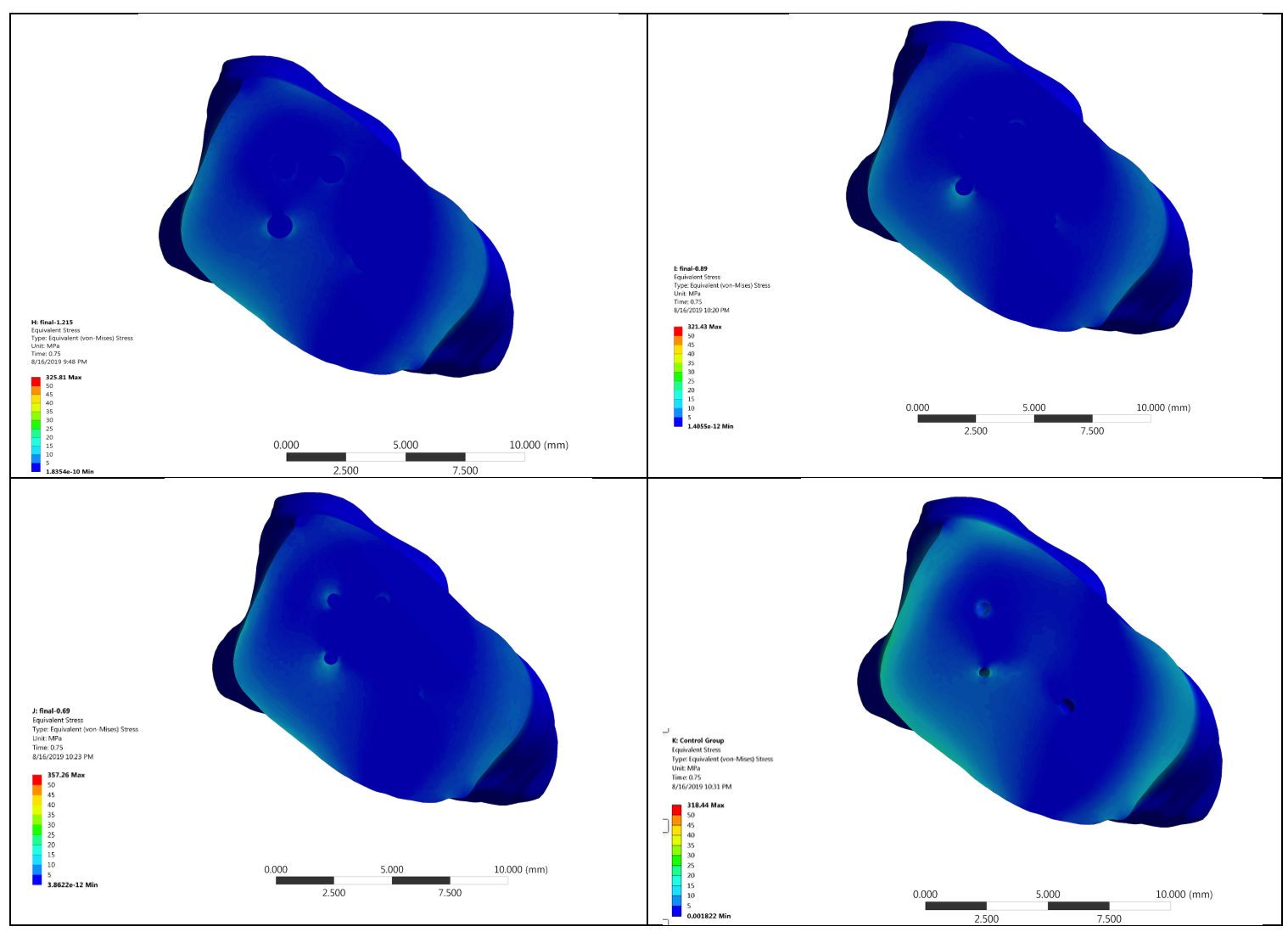

Figure 16: $1.3 \mathrm{~mm}$ below the CEJ (Axial view) 


\section{Discussion}

Kakehashi et al, has shown that microorganisms were the etiology of pulpal and periapical disease (22). The goal of endodontics is to disinfect and debride the inflamed/infected/necrotic pulpal tissue from the root canal system and facilitate the immune system to heal upon removal of the source of the irritation and infection. Various endodontic instruments have been used to achieve this goal. These instruments have improved significantly over time with the development of new technologies in the field of endodontics. According to Siquirea et al, instrumentation by itself can effectively decrease the microbial load in the root canal system by $90 \%(23)$.

However, there are still many controversies about the type, size, and taper of rotary instruments that are necessary to achieve the ideal treatment outcome. There have also been conflicting results about the impact of the root canal preparation on treatment outcome (38). Petiette et al, concluded that maintaining the original canal shape improves the long-term prognosis of endodontically treated teeth. Orstavik et al, could not verify the influence of final preparation size on treatment outcome (39). Peters et al also found that there was no treatment outcome difference between three different NiTi instruments (Lightspeed, ProFile 0.04, GT Rotary) (24). As a result, the ideal NiTi instrumentation size to produce a superior treatment outcome is yet to be determined.

It is important for the clinician to understand the negative effects of root canal system instrumentation on the overall strength of the remaining tooth structure. With the increase of rotary instrumentation taper, inevitably more dentin is removed and root structure is weakened. Gher et al and Cohen et al, have established the significantly higher incidence of vertical root fracture with previously endodontically treated teeth (27). Diagnosing fractured teeth is often challenging and complicated. Fractured teeth can remain undiagnosed for many years after completion of endodontic therapy (29). As a result, there have been many recent efforts to perform endodontic therapy as conservative as possible to minimize the risks of tooth fracture.

Despite a successful endodontic treatment, patients will not be served well if the remaining tooth structure fails to withstand masticatory forces. Prior to the emergence of implantology in mainstream dentistry, root canal therapy, along with core and full cuspal coverage, was a common treatment option of marginally restorable teeth. However, the success of implants in recent years is making treatment decisions more difficult for both patients and clinicians. Therefore, this research focuses on assessing fracture resistance of endodontically treated maxillary first molars with the aim of offering ways to conserve tooth structure, with the ultimate goal of increasing the longevity of endodontically treated teeth (5).

This study evaluated the effect of rotary file taper sizes on the fracture resistance of endodontically treated teeth using FEA to measure the amount of stress 
and strain exerted on dentin near the pre-cervical area and alveolar crest of maxillary first molars. This critical zone is roughly $4 \mathrm{~mm}$ above the crestal bone and extends $4 \mathrm{~mm}$ apical from the crest of the bone. Dedicating this study to the pre-cervical area has a four-fold rationale: 1) The effect of ferrule, 2) the proximity of dentin tubule orifices at the CEJ, 3) the significant reduction in enamel thickness, and 4) the concentration of all masticatory forces in this area $(5,8)$.

In this study, an intact maxillary first molar and endodontically treated maxillary first molar with three different rotary instruments were generated based on microcomputed tomographic data. Based on the results of this study, the null hypothesis was rejected. In the cervical region, Von Mises stress was concentrated on the margin of the palatal root significantly less in the $\mathrm{V}$-Taper group and the control group in comparison to ProTaper and Vortex Blue. With the reduction of dentinal wall removal, the stress concentration was decreased. At the CEJ level, the ProTaper group showed the most amount of stress concentration surface area in comparison to the other groups, and with the V-Taper group having the closest stress concentration to intact tooth.

The distribution of the maximum principal stress is shown in Figure 12-16. The concentrations of tensile stress were located on the palatal portion of the palatal root, the root furcation, and the distal portion of the distal root. Previous studies have shown that the maximum principal stress in the mesiobuccal root was significantly more than other areas (36). However, in this study, the maximum stress was on different areas possibly due to the simulation of the chewing forces rather than applying direct vertical forces.

The three groups of file sizes in this study all have the same tip size $(0.25 \mathrm{~mm})$, however, their MFD at D16 are significantly different, with ProTaper being the largest file and V-Taper being the smallest near D16. Therefore, within the limited scope of this study, it can be concluded that preserving dental hard tissue, particularly pre-cervical dentin, in root canal treatment is a viable method to reduce the maximum principal stress and to reduce the stress concentration near this vulnerable area. This was a critical area to disperse stress through the long axis of the tooth. V-taper files are designed to decrease the amount of tooth structure removal in pre-cervical dentin to minimize the overall weakening effects of endodontic treatment. 


\section{Chapter 5}

\section{Conclusion}

This study attempted to elucidate the link between increased rotary instrument taper with the increased risk of stress concentration at the CEJ level using Finite Element Analysis in the maxillary first molar model. Taper size appears to be one of many factors which affect the distribution of forces along root structures. Preserving dental hard tissue significantly reduced the stress concentration in the cervical region and increased the ultimate fracture resistance of dentin. The FEA method has many limitations. Therefore, the clinical application of results found in this study need further investigation on natural tooth structure and ideally under masticatory forces in the oral cavity. 


\section{Works Cited}

$1 \quad$ Kishen A. Mechanisms and risk factors for fracture predilection in endodontically treated teeth. Endod Top 2006;13(1):57-83. Doi: 10.1111/j.1601-

1546.2006.00201.x.

2 Glossary of Endodontic Terms - American Association of Endodontics. 2012.

3 Glossary of Endodontic Terms - American Association of Endodontists. Available at: https://www.aae.org/specialty/clinical-resources/glossary-endodontic-terms/. Accessed September 15, 2019, 2015.

4 Mathew S, Thangavel B, Mathew C, Kailasam S, Kumaravadivel K Das A. Diagnosis of cracked tooth syndrome. J Pharm Bioallied Sci 2012;4(6):242. Doi: 10.4103/0975-7406.100219.

$5 \quad$ Clark D. The Epidemic of Cracked and Fracturing. Dent Today 2007;(4):48-52.

6 Touré B, Faye B, Kane A W, Lo C M Niang B, Boucher Y. Analysis of reasons for extraction of endodontically treated teeth: A prospective study. J Endod 2011;37(11):1512-5. Doi: 10.1016/j.joen.2011.07.002.

7 Ree M, Schwartz R. The Endo-Restorative Interface: Current Concepts. Dent Clin North Am 2010;54(2):345-74. Doi: 10.1016/j.cden.2009.12.005.

8 Yan W, Montoya C, Oilo M, Ossa A, Paranjpe A, Zhang H Arola D. Contribution of Root Canal Treatment to the Fracture Resistance of Dentin. J Endod 2019;45(2):189-93. Doi: 10.1016/j.joen.2018.10.004.

9 Javaheri $\mathrm{H}$, Javaheri G. A Comparison of Three Ni-Ti Rotary Instruments in Apical Transportation. J Endod 2007. Doi: 10.1016/j.joen.2006.05.004.

10 Zhang Y, Liu Y, She Y, Liang Y, Xu F Fang C. The Effect of Endodontic Access Cavities on Fracture Resistance of First Maxillary Molar Using the Extended Finite Element Method. J Endod 2019;45(3):316-21. Doi: 10.1016/j.joen.2018.12.006.

11 Sabeti M, Kazem M, Dianat O Bahrololumi N, Begloo A, Rahimipour K Dehnavi F. Impact of Access Cavity Design and Root Canal Taper on Fracture Resistance of Endodontically Treated Teeth: An Ex Vivo Investigation. J Endod 2018;44(9):14026. Doi: 10.1016/j.joen.2018.05.006.

12 Clark D, Khademi J, Featherstone R. Print Article Page 2 of 10. Dent Today 2009;(October):1-10.

13 Hu T, Cheng R, Shao M, Yang H, Zhang R, Gao Q Guo L. Application of Finite Element Analysis in Root Canal Therapy. ResearchGate 2012;(August):1-23. Doi: $10.5772 / 9994$.

14 Grossman L. I. Endodontics 1776-1976: a bicentennial history against the background of general dentistry. Journal of American Dental Association 1976. Doi: 10.14219/jada.archive.1976.0606.

15 Kuzekanani M. Review Article 2017:71-81. Doi: 10.4103/jispcd.JISPCD.

16 Auricchio F, Taylor R L., Lubliner J. Shape-memory alloys: macromodelling and numerical simulations of the superelastic behavior 1997;146(3-4):281-312. Doi: 
10.1016/S0045-7825(96)01232-7.

17 Walia $\mathrm{H}$, Brantley W Gerstein H. An initial investigation of the bending and torsional properties of nitinol root canal files. J Endod 1988. Doi: 10.1016/S00992399(88)80196-1.

18 Thompson S. A. An overview of nickel-titanium alloys used in dentistry. Int Endod J 2000. Doi: 10.1046/j.1365-2591.2000.00339.x.

19 Hulsmann M, Peters O, Dummer P. Mechanical preparation of root canals: shaping goals, techniques and means. Endod Top 2005. Doi: 10.1111/j.16011546.2005.00152.x.

20 Haapasalo $M$, Shen Y. Evolution of nickel-titanium instruments: from past to future. Endod Top 2013. Doi: 10.1111/etp.12049.

21 Gavini G, Santos M, Caldeira C Machado M, Freire L, Iglecias E, Peters O, Candeiro G. Nickel-titanium instruments in endodontics: a concise review of the state of the art. Braz Oral Res 2018. Doi: 10.1590/1807-3107bor-2018.vol32.0067.

22 Ha J H, Kim S K, Cohenca N Kim H C. Effect of R-phase heat treatment on torsional resistance and cyclic fatigue fracture. J Endod 2013. Doi:

10.1016/j.joen.2012.11.028.

23 Kayahan B, Ayhan T, Guven P Tanalp J. Comparison of the amount of apically extruded debris during retreatment using different nickel-titanium systems and hand instruments in teeth with wide apices. Biomed Res 2017.

24 Peters O. A., Gluskin A. K., Weiss R. A. Han J. T. An in vitro assessment of the physical properties of novel Hyflex nickel-titanium rotary instruments. Int Endod J 2012. Doi: 10.1111/j.1365-2591.2012.02067.x.

25 Kakehashi S, Stanley H. R Fitzgerald R. J. The effects of surgical exposures of dental pulps in germ-free and conventional laboratory rats. Oral Surgery, Oral Med Oral Pathol 1965. Doi: 10.1016/0030-4220(65)90166-0.

26 Siqueira J F, Lima K C, Magalhäes F A.C., Lopes H P De Uzeda M. Mechanical reduction of the bacterial population in the root canal by three instrumentation techniques. J Endod 1999. Doi: 10.1016/S0099-2399(06)81166-0.

27 Kovac J, Kovac D. Effect of irrigating solutions in endodontic therapy. Bratislava Med J 2011.

28 Card S, Sigurdsson A, Orstavik D Trope M. The Effectiveness of Increased Apical Enlargement in Reducing Intracanal Bacteria. J Endod 2002;28(11):779-83. Doi: 10.1109/PESC.1999.789008.

29 Coldero L. G., McHugh S, Mackenzie D Saunders W. P. Reduction in intracanal bacteria during root canal preparation with and without apical enlargement. Int Endod J 2002;35(5):437-46. Doi: 10.1046/j.1365-2591.2002.00496.x.

30 Gher M. E., Dunlap R. M., Anderson M. H. Kuhl L. V. Clinical survey of fractured teeth. J Am Dent Assoc 1987. Doi: 10.14219/jada.archive.1987.0006.

31 Meister F, Lommel T Gerstein H. Diagnosis and possible causes of vertical root fractures. Oral Surgery, Oral Med Oral Pathol 1980. Doi: 10.1016/00304220(80)90056-0.

32 Tamse A. Vertical root fractures in endodontically treated teeth: diagnostic signs and clinical management. Endod Top 2006. Doi: 10.1111/j.1601- 
1546.2006.00200.x.

33 Tamse A, Fuss Z, Lustig J Kaplavi J. An evaluation of endodontically treated vertically fractured teeth. J Endod 1999. Doi: 10.1016/S0099-2399(99)80292-1.

34 Cheron R A, Marshall S J, Goodis H E Peters O. Nanomechanical properties of endodontically treated teeth. J Endod 2011. Doi: 10.1016/j.joen.2011.08.006.

35 Hu J, P. Chun Y, Al Hazzazzi T, Simmer J. Enamel formation and amelogenesis imperfecta. Cells Tissues Organs 2007;186(1):78-85. Doi: 10.1159/000102683.

36 Kingma C. Influence of Taper on the Flexibility of Nickel- Titanium Rotary Files. Marquette Univ 2014;249:1-35.

37 Corsentino G, Pedullà E, Castelli L Liguori M, Spicciarelli V, Martignoni M Ferrari M, Grandini S. Influence of Access Cavity Preparation and Remaining Tooth Substance on Fracture Strength of Endodontically Treated Teeth. J Endod 2018;44(9). Doi: 10.1016/j.joen.2018.05.012.

38 Shantiaee Y, Dianat O, Mosayebi G, Namdari M, Tordik P. Effect of Root Canal Preparation Techniques on Crack Formation in Root Dentin. J Endod 2019;45(4):447-52. Doi: 10.1016/j.joen.2018.12.018.

39 Hegde N, Shetty S Godara N. Evaluation of fracture strength of tooth roots following canal preparation by hand and rotary instrumentation - an in vitro study. Endodontology 2008;20(1):22-9.

40 Srirekha A Bashetty K. Infinite to finite: An overview of finite element analysis. Indian J Dent Res 2010;21(3):425. Doi: 10.4103/0970-9290.70813.

41 The Occlusal Function - The Occlusal Function mastication-ppp.net. Available at: http://mastication-ppp.net/en/overview/welcome/. Accessed September 13, 2019 , n.d. 